\title{
Determination of Thermal Material Properties for the Numerical Simulation of Cutting Processes
}

Michael Storchak ( $\nabla$ michael.storchak@ifw.uni-stuttgart.de )

Universitat Stuttgart https://orcid.org/0000-0002-6603-1710

Thomas Stehle

Universitat Stuttgart

Hans-Christian Möhring

Universitat Stuttgart

\section{Research Article}

Keywords: Cutting, thermal properties, simulation

Posted Date: May 18th, 2021

DOI: https://doi.org/10.21203/rs.3.rs-488924/v1

License: (c) (1) This work is licensed under a Creative Commons Attribution 4.0 International License. Read Full License

Version of Record: A version of this preprint was published at The International Journal of Advanced Manufacturing Technology on September 24th, 2021. See the published version at https://doi.org/10.1007/s00170-021-08021-2. 


\title{
Determination of thermal material properties for the numerical simulation of cutting processes
}

\author{
Michael Storchak ${ }^{a^{*}}$, Thomas Stehle ${ }^{a}$, Hans-Christian Möhringa \\ a Institute for Machine Tools, University of Stuttgart, Stuttgart, Germany \\ *corresponding author: michael.storchak@ifw.uni-stuttgart.de
}

\begin{abstract}
Thermal properties of work materials, which depend significantly on the change in cutting temperature, have a considerable effect on thermal machining characteristics. Therefore, the thermal properties used for the numerical simulation of the cutting process should be determined depending on the cutting temperature. To determine the thermal properties of the work materials, a methodology and a software-implemented algorithm were developed for their calculation. This methodology is based on analytical models for the determination of tangential stress in the primary cutting zone. Based on this stress and experimentally or analytically determined cutting temperatures, thermal properties of the work material were calculated, namely the coefficient of the heat capacity as well as the coefficient of thermal conductivity. Three variants were provided for determining the tangential stress: based on the normal stress calculated using the Johnson-Cook constitutive equation, based on the experimentally determined cutting and thrust forces as well as by directly calculating the tangential stress. The thermal properties were determined using the example of three different materials: AISI 1045 and AISI 4140 steel as well as Ti10V2Fe3Al titanium alloy (Ti-1023). With the developed FE cutting model, the deviation between experimental and simulated temperature values ranged from approx. $7.5 \%$ to $14.4 \%$.
\end{abstract}

Keywords: Cutting, thermal properties, simulation

\section{Introduction}

Over the last decades, considerable improvements in modeling have turned numerical simulations of various machining processes, e.g. using the finite element method (FEM), into powerful tools for investigating machining characteristics (mainly cutting forces and temperatures), tool wear, physical-mechanical characteristics of workpiece boundary layers, etc. [1], [2], [3], [4]. In order to obtain machining characteristics corresponding to the specific modeled processes of material removal, it is necessary to use realistic values of cutting model parameters. Whereas there has been extensive research into establishing the parameters 
of the material model, the friction model and the fracture model of the work material (see e.g. [5], [6], [7], [8] and many others), little attention has been given to determining the thermal properties of the material for modeling the cutting process. Yet, the thermal properties of the material to be machined have a significant impact on the cutting process characteristics and, particularly on the value of the cutting temperature. The simulation of the latter, along with other equally important characteristics, has been given special attention [9], [10], [11], [12].

This paper presents investigations into establishing the thermal properties of the work materials, especially for the modeling of cutting processes. In addition, a method for determining these properties and the simulation results for these thermal properties are described here using the example of orthogonal cutting.

\section{Methods for the determination of thermal properties}

The focus of several publications has been on determining the thermal properties of different materials. The general procedure for establishing these properties is described in [13], for example. The thermal properties of materials have mainly been determined by experiment (see e.g. [14], [15], [16]). However, there have also been experiments to establish these properties theoretically or analytically [17], [18] as well as to numerically simulate and calculate the thermal properties of different kinds of steel (see e.g. [19]).

Most publications on the modeling of cutting processes have taken the thermal properties of the work material from the constant values included as standard in the simulation software (see e.g. [20], [21], [22], [23]). In the studies dealing with the analytical modeling of cutting processes (see e.g. [5], [21], [24], [25], [26], [27]), the properties required have been established as constant values based on similar sources. These values have been determined with common methods for the examination of material properties (see [15], [28], [29], [30], [31] and many others). The values of the thermal properties have been established at a fixed temperature of the material, mainly at room temperature. In addition, it is known that the thermal properties of materials such as specific heat, thermal expansion and thermal conductivity also change significantly with varying temperature of the examined material [14], [15], [17]. If it is not taken into consideration that the thermal properties of the work material change when its temperature changes, fundamental errors occur regarding the determination of thermal flows in this material. In turn, this leads to considerable errors when establishing the temperature and the kinetic characteristics of cutting processes, tool wear, etc.

In rather less known studies, changes in the thermal properties of the work material with varying 
temperature have been taken into account [2], usually compiled in a table and used for simulating the values of the corresponding cutting temperature (see e.g. [32]). Moreover, the data have been approximated and mostly used as a simple equation, but also as a higher equation in the modeling [2], [27], [33], [34].

It also has to be noted here that the analyzed literature sources have been based on the assumption that the thermal properties to be defined are constant within the boundaries of the test piece.

\section{Methodology for identifying thermal properties}

The specific characteristic of the material deformation and the subsequent material breaking during the cutting in heterogeneous shearing processes is that areas with different states of stress-strain arise and thus with a considerably different deformation in corresponding cutting zones [35], [36], [38]. In the same way, the temperature of the material in the cutting zones and their areas differs considerably [22], [39], [43]. Under certain cutting conditions, this leads to a hardening of the material as well as to a softening of the material among other things. The thermal properties of the material and how they vary with temperature depend basically on its state of stress-strain. The condition of the material in different cutting zones differs greatly from the usual, often undeformed condition in which its thermal properties are generally measured. As such material conditions can only be obtained during the cutting process [38], the thermal properties of the material have to be established during the corresponding machining processes.

For establishing the thermal properties of the work material, which are necessary to simulate different cutting processes, it was suggested to determine by experiment the cutting temperature in the respective zones based on the analytical description of the stress-strain state of the material [36], [38] in the cutting zones Fig. 1. In this case, it was necessary to find out for which area or rather cutting zone the corresponding calculations and temperature measurements must be carried out. Naturally, it made sense to choose that cutting zone or that area of the zone in which there is a constant temperature distribution, the measuring point is as accessible as possible and the measuring process itself is comfortable on the whole. A constant temperature distribution depends basically on a homogeneous stress-strain state of the material [38], [39], [40]. A homogeneous stress-strain state of the work material and a resulting constant temperature occurs in those cutting zones with predominantly adiabatic deformation conditions leading to material hardening or isothermal deformation conditions leading to material softening. Under these conditions, the material is only in the primary cutting zone [38], [41]. In this zone, the material to be machined is under all-around 
compression. This condition provides for a uniform distribution of deformations, stresses and temperatures throughout the entire primary cutting zone. Possible irregularities in the distribution of these characteristics accompanying the machining of such difficult-to-machine materials as, for example, titanium and nickel alloys, austenitic steels, etc., arise after the material to be machined has left the primary cutting zone, i.e. after the final chip formation. This occurs already in the stagnant area of the secondary cutting zone [38], [41].

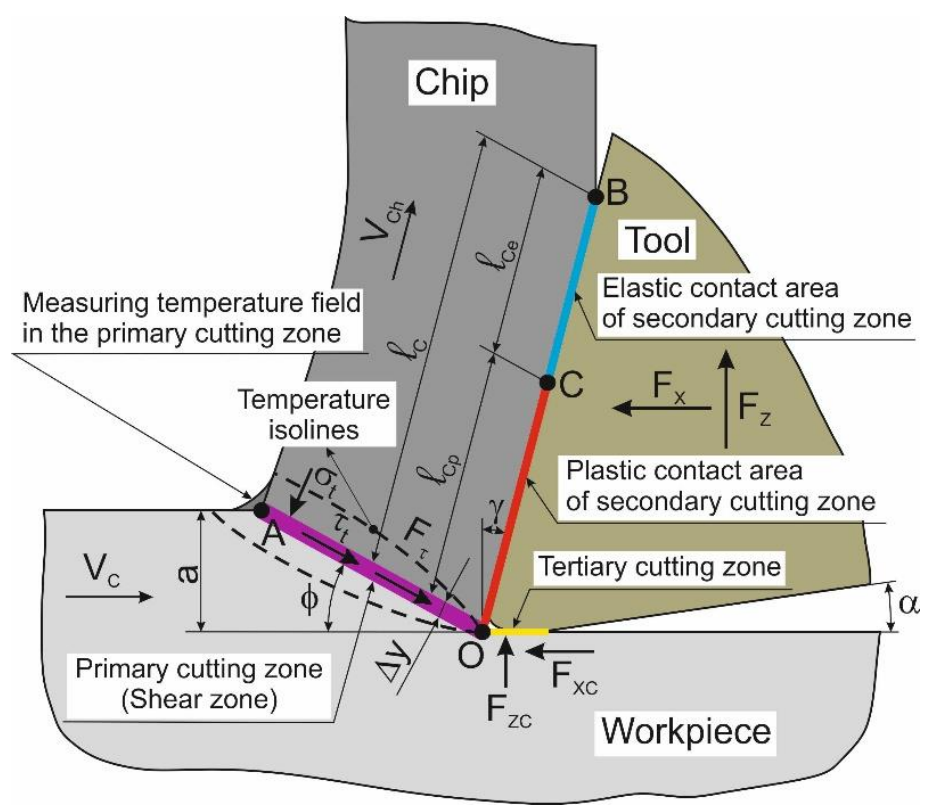

Fig. 1: Layout of cutting zones.

The temperature distribution within the primary zone, inside the area bounded by the indicated temperature isolines (see Fig. 1), is approximately constant compared with the temperature distribution in the secondary and tertiary cutting zones, in which there is a temperature gradient of up to $5^{\circ} \mathrm{C} / \mu \mathrm{m}$ [13], [39], [42], [43]. Moreover, the accessibility to the temperature measurement of the primary cutting zone is considerably better and more comfortable than in other cutting zones, because the temperature can be measured at the exterior surface of the chip during the transition from workpiece material to chip (see Fig. 1). For example, the temperature at the exterior surface of the chip in this measuring point is the same as in the primary cutting zone. This occurs if the chip thickness is within the conventional range, the chip forming process is constant and the temperature at this measuring point has reached the steady-state condition [40], [44]. 
The temperature of the deformed material in the primary cutting zone was in proportion to the specific deformation work [38], [39]:

$$
T_{d 0}=\frac{A_{w}}{C_{V}} \cdot K_{P \varepsilon}=\frac{\tau_{t} \cdot \varepsilon_{w}}{C_{V}} \cdot K_{P \varepsilon}
$$

where $A_{w}$ is the specific deformation work, $C_{V}$ is the coefficient of the specific volumetric heat capacity of the work material, $\tau_{t}$ is the tangential stress in the primary cutting zone or rather the specific tangential force in this zone, $\varepsilon_{w}$ is the true final strain, $K_{P_{\varepsilon}}$ is the coefficient of heat flow from the primary cutting zone into the workpiece.

The true final strain $\varepsilon_{w}$ in the case of adiabatic material hardening was established with the chip compression ratio $K_{a}[6],[35],[36]:$

$$
\varepsilon_{w}=\frac{K_{a}+\frac{1}{K_{a}}-2 \cdot \sin \gamma}{\cos \gamma}, K_{a}=\frac{a_{C}}{a}
$$

where $a$ is the undeformed chip thickness (depth of cut), $a_{c}$ is the chip thickness, $\gamma$ is the tool orthogonal rake angle of the tool wedge (see Fig. 1).

The coefficient of heat flow from the primary cutting zone into the workpiece $K_{P_{\varepsilon}}$ was defined by the following equation [38]:

$$
\begin{gathered}
K_{P \varepsilon}=\frac{1}{1+\frac{1-e^{-P_{e} \cdot \tan \phi}}{P_{e} \cdot \tan \phi}}=\frac{1}{1+\frac{\cot \phi}{P_{e}}}, \\
P_{e}=\frac{V_{C} \cdot a}{\omega},
\end{gathered}
$$

where, $P_{e}$ is the Péclet number (Péclet criterion), $\phi$ is the shear angle, $V_{C}$ is the cutting speed, $\omega$ is the coefficient of thermal diffusivity, defined as the quotient of the coefficient of thermal conductivity and the coefficient of specific volumetric heat capacity.

The shear angle $\phi$ was determined using the chip compression ratio $K_{a}$ and the tool orthogonal rake angle $\gamma$.

$$
\phi=\arctan \left(\frac{\frac{1}{K_{a}} \cdot \cos \gamma}{1-\frac{1}{K_{a}} \cdot \sin \gamma}\right) .
$$


As the temperature at the exterior surface of the chip (see Fig. 1) was established by experiment, the coefficient of the specific volumetric heat capacity $C_{V}$ could be calculated as follows:

$$
C_{V}=\frac{\tau_{t} \cdot \varepsilon_{w} \cdot K_{P \varepsilon}}{T_{\text {dmeas }}}
$$

The stress-strain state of the work material in the primary cutting zone during cutting could be clearly established with the tangential stress or rather the specific tangential force $\tau_{t}$ (see Fig. 1) and the true final strain $\varepsilon_{w}$ [35], [36], [38]. The tangential stress $\tau_{t}$ was determined in three different ways:

due to the normal stress $\sigma_{t}$ calculated using a well-known constitutive equation (e.g. Johnson-Cook [45]) $(\mathrm{JC})$

based on the resultant forces determined by experiment, e.g. $F_{X}$ and $F_{Z}$ in the case of orthogonal cutting (MF);

by directly calculating the tangential stress $\tau_{t}(\mathrm{TS})$.

According to the first method $(\mathrm{JC})$, the normal stress $\sigma_{t}$ prevailing in the primary cutting zone during the machining of material was established using a constitutive equation, in this case with the Johnson-Cook constitutive equation [45]:

$$
\sigma_{t}=\left(A+B \cdot \varepsilon^{n}\right) \cdot\left[1+C \cdot \ln \left(\frac{\dot{\varepsilon}}{\dot{\varepsilon}_{0}}\right)\right] \cdot\left[1-\left(\frac{T_{\text {dmeas }}-T_{r}}{T_{m}-T_{r}}\right)^{m}\right]
$$

where $\sigma_{t}$ is the normal stress, $A$ is the initial yield stress, $B$ is the stress coefficient of strain hardening, $n$ is the power coefficient of strain hardening, $C$ is the strain rate coefficient, $m$ is the power coefficient of thermal softening, $\varepsilon$ is the strain, $\dot{\varepsilon}$ is the strain rate, $\dot{\varepsilon}_{0}$ is the reference value of strain rate, $T_{\text {dmeas }}$ is the actually measured temperature in the primary cutting zone, $T_{r}$ is the reference or room temperature and $T_{m}$ is the melting temperature of the material to be machined (work material).

The constitutive equation contains five constants: $A, B, n, C$ and $m$, which can be determined by experiment (see e.g. [6]). The tangential stress $\tau_{t}$ was calculated through the normal stress $\sigma_{t}$ as follows [6], [38]:

$$
\tau_{t}=\frac{\sigma_{t}}{\sqrt{3}}
$$

The strain rate $\dot{\varepsilon}$ from Equation (7) could be calculated in two different ways, either due to Oxley's machining 
theory [6], [35], [46], [47], [48]:

$$
\dot{\varepsilon}=\frac{C_{0} \cdot V_{C} \cdot \cos \gamma \cdot \sin \phi}{\sqrt{3} \cdot a \cdot \cos (\phi-\gamma)},
$$

where $C_{0}$ is the thickness ratio of the primary cutting zone,

or due to Zorev's machining theory [6], [36]:

$$
\dot{\varepsilon}=\frac{V_{C} \cdot \cos \gamma}{\sqrt{3 \cdot \Delta y \cdot \cos (\phi-\gamma)},}
$$

where $\Delta y$ is the thickness of the primary cutting zone (see Fig. 1).

If it was considerably difficult or impossible to directly measure the thickness of the primary cutting zone $\Delta y$, the value was determined with the following inequality [6]:

$$
\frac{a}{10 \cdot \sin \phi} \leq \Delta y \leq \frac{a}{2 \cdot \sin \phi} \text {. }
$$

Instead of using the classic Johnson-Cook equation, it would also be possible to apply the modified equations developed in the last years (see e.g. [49], [50], [51]).

According to the second method (MF), the tangential stress $\tau_{t}$ in the primary cutting zone was determined due to the resultant forces established by experiment [36], [38]:

$$
\tau_{t}=\frac{\left(F_{X}-F_{X C}\right) \cdot \cos \phi-\left(F_{Z}-F_{Z C}\right) \cdot \sin \phi}{a \cdot w} \cdot \sin \phi,
$$

where $w$ is the cutting width, $F_{X}$ and $F_{Z}$ are the experimental cutting and thrust forces respectively (in the case of orthogonal cutting), $F_{X C}$ and $F_{Z C}$ are the cutting and thrust forces at the clearance face of the tool wedge (in the tertiary cutting zone) respectively.

The forces $F_{X C}$ and $F_{Z C}$ in the tertiary cutting zone are determined by extrapolating the dependence of respective forces on the depth of cut to the zero value of this depth of cut [36], [37], [41].

In the third method (TS), the tangential stress $\tau_{t}$ was directly calculated according to the following equation [38]:

$$
\tau_{t}=\left\{\begin{array}{l}
R_{t} \cdot e^{-m_{h} \cdot\left(\frac{\varepsilon_{w}}{\varepsilon_{\tau \max }}-1\right)} \cdot\left[\varepsilon_{\tau \max }^{m_{h}} \cdot \frac{K_{\varepsilon} \cdot A}{1+m_{h}} \cdot\left(1-\frac{\varepsilon_{\tau \max }}{\varepsilon_{w}}\right)+\frac{\ln \left(1+m_{h}\right)}{A_{1} \cdot B_{\tau} \cdot \varepsilon_{w}}\right], \varepsilon_{w}>\varepsilon_{\tau \max } \\
R_{t} \cdot \ln \left(1+\frac{A \cdot A_{1} \cdot B_{\tau} \cdot K_{\varepsilon}}{1+m_{h}} \cdot \varepsilon_{w}^{m_{h}+1}\right) \cdot \frac{1}{A_{1} \cdot B_{\tau} \cdot \varepsilon_{w}},, \varepsilon_{\tau \max }>\varepsilon_{w}
\end{array}\right.
$$


where $R_{t}$ is the true ultimate strength, $m_{h}$ is the empirically established parameter of the material deformation hardening, $B_{\tau}$ is the empirical constant taking account of the joint effect of strain rate and temperature on the yield point, $K_{\varepsilon}$ is the empirical constant regarding the effect of the strain rate at a partly constant mean temperature. The dimensionless complexes $A_{1}$ and $A$ were defined with the following equation [38], [39], [41]:

$$
\begin{gathered}
A=\frac{1}{\sqrt{3} \cdot[\sqrt{3} \cdot \ln (1+\delta)]^{m_{h}}}, \\
A_{1}=\frac{R_{t}}{C_{V} \cdot T_{m}}
\end{gathered}
$$

The experimental coefficients $B_{\tau}$ and $K_{\varepsilon}$ were established using mechanical tensile/compression tests according to the methodology in [6], [38]. The maximum deformation of the work material to be reached under isothermal deformation conditions in the primary cutting zone was calculated with the following equation [39], [41]:

$$
\varepsilon_{\tau \max }=\left[\frac{m_{h} \cdot\left(1+m_{h}\right)}{A \cdot A_{1} \cdot K_{\varepsilon} \cdot B_{\tau}}\right]^{\frac{1}{1+m_{h}}},
$$

However, the coefficient of mass specific heat capacity $C_{m}$ is mostly used in commercial and other software for the simulation of machining processes. $C_{m}$ of $C_{V}$ was converted according to the following equation:

$$
C_{m}=\frac{C_{V}}{\rho},
$$

where $\rho$ is the density of the material.

By defining the coefficient of the specific heat capacity, it was possible to determine a further thermal property of the work material, namely the coefficient of thermal conductivity $\lambda$. Zorev*s machining theory [36] and the extended Oxley's machining theory [6], [35], [46], [47], [48] were used for that. Based on the mathematical composition of the theory, the coefficient of thermal conductivity $\lambda$ was calculated with the following system: 


$$
\left\{\begin{array}{l}
\lambda=\frac{\rho \cdot C_{m} \cdot V_{C} \cdot a \cdot \tan \phi}{10^{\frac{0.5-\beta}{0.35}}}, 0.4 \leq R_{T} \cdot \tan \phi \leq 10.0 \\
\lambda=\frac{\rho \cdot C_{m} \cdot V_{C} \cdot a \cdot \tan \phi}{10^{\frac{0.3-\beta}{0.15}}}, R_{T} \cdot \tan \phi>10.0
\end{array}\right.
$$

The proportion of heat conducted into the workpiece $\beta$ (a similar quantity like the coefficient of heat flow from the primary cutting zone into the workpiece $K_{P_{\varepsilon}}$, see Equation (3)) was calculated with the following equation:

$$
\beta=1-\frac{\left(T_{\text {dmeas }}-T_{r}\right) \cdot \cos (\phi-\gamma) \cdot \rho \cdot C_{m} \cdot a \cdot w}{F_{\tau} \cdot \cos \gamma \cdot \eta},
$$

in addition, the thermal number $R_{T}$ was determined as follows:

$$
R_{T}=\frac{\rho \cdot C_{m} \cdot V \cdot a}{\lambda}
$$

where $\eta$ is the parameter to scale the average temperature rise at the shear plane (when fulfilling the conditions of orthogonal cutting).

The cutting force $F_{\tau}$ (see Fig. 1) acting in the primary cutting zone was defined as follows:

$$
F_{\tau}=\frac{\tau_{t} \cdot a \cdot w}{\sin \phi}
$$

The coefficient of thermal expansion, which is also necessary for simulating cutting processes, can be established using a simulation-aided design of experiments (DOE) (not presented in this paper). The DOE method is determined based on the temperatures measured in the primary cutting zone as well as the coefficients of specific heat capacity $C_{V}$ and thermal conductivity $\lambda$ defined in advance (see Chapter 6 ).

\section{Test set-up}

The device for conducting the experimental analyses was designed and assembled for establishing the cutting temperature at the exterior surface of the chip in the terminal area of the primary cutting zone. The measuring device consisted of two set-ups: one for conducting the cutting tests and one for the calibration of the measuring system.

\subsection{Cutting tests}

The experimental investigations into the determination of cutting temperatures were carried out in the machining of AISI 1045 and AISI 4140 steel as well as Ti-1023 titanium alloy (Ti10V2Fe3Al) using the test 
stand for orthogonal and oblique cutting [37], [40]. Fig. 2 shows the used test facility with the measuring equipment for establishing the resultant forces and cutting temperatures [37], [44]. The workpiece was clamped into a three-component dynamometer, type 9263 by Kistler, which was used for measuring the resultant forces. The cutting process was carried out using the tool with a clamped changeable cemented carbide insert SNMG-SM-1105 by Sandvik Coromant. The geometry of the tool wedge necessary for cutting was guaranteed by positioning and grinding the tool orthogonal clearance of the wedge. The tool orthogonal clearance was $8^{\circ}$, and the radius of cutting edge rounding was $20 \mu \mathrm{m}$ in all tests. The tool orthogonal rake angle was changed from $-10^{\circ}$ to $10^{\circ}$ in steps of $10^{\circ}$ in order to guarantee different values of the true final strain $\varepsilon_{w}$ of the work material in the primary cutting zone.

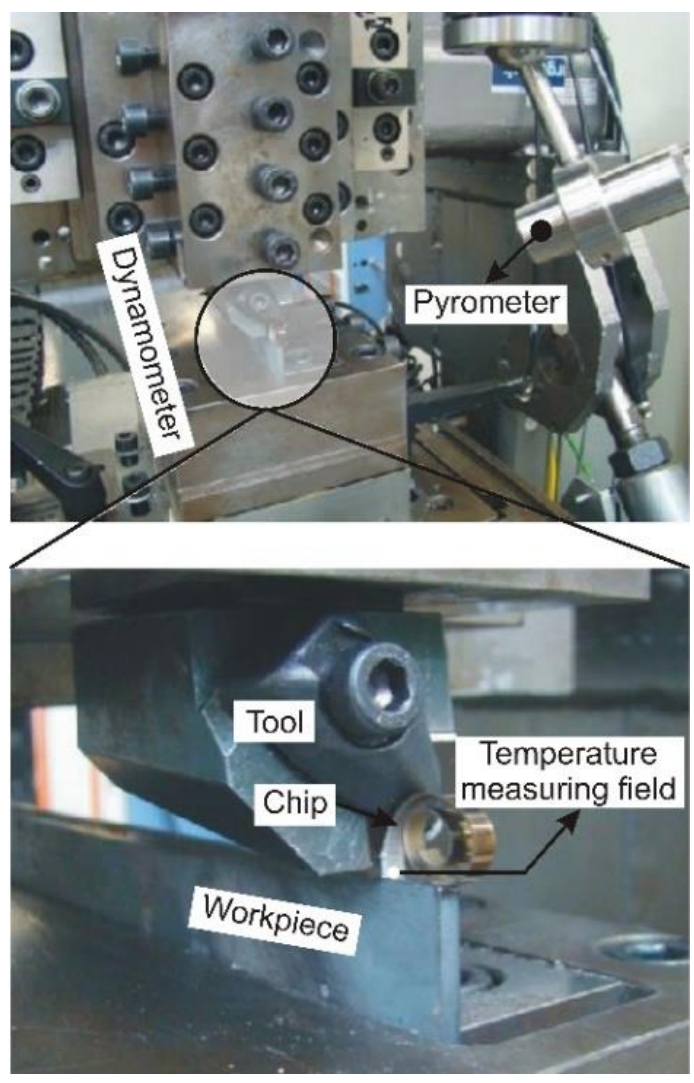

Fig. 2: Experimental set-up for temperature measurement [44].

The cutting temperature was measured with a high-speed pyrometer, IGA-740 LO by LumoSense, at the exterior surface of the chip (see the measuring field in Fig. 2). The measuring field of the pyrometer ranged from $0.5 \mathrm{~mm}-0.8 \mathrm{~mm}$. The time resolution was $6 \mu \mathrm{sec}$. The cutting parameters used in the experiments are given in Table 1. 
Table 1: Cutting parameters in experimental tests.

\begin{tabular}{|c|c|c|c|c|c|c|c|c|}
\hline \multirow{2}{*}{ Material } & \multicolumn{3}{|c|}{$\begin{array}{c}\text { Cutting speed, } V_{C} \\
{[\mathrm{~m} / \mathrm{min}]}\end{array}$} & \multicolumn{3}{c|}{$\begin{array}{c}\text { Depth of cut, a } \\
\text { [mm] }\end{array}$} & \multicolumn{2}{c|}{$\begin{array}{c}\text { éclet number, } P_{e} \\
{[-]}\end{array}$} \\
\cline { 2 - 9 } & max. & min. & step & max. & min. & step & max. & min. \\
\hline AISI 1045 & 192 & 48 & 48 & 0.2 & 0.1 & 0.05 & 60 & 10 \\
\hline AISI 4140 & 144 & 48 & 48 & 0.2 & 0.1 & 0.05 & 80 & 10 \\
\hline Ti-1023 & 96 & 32 & 16 & 0.15 & 0.05 & 0.05 & 30 & 3.34 \\
\hline
\end{tabular}

\subsection{Calibration}

During the cutting process, the work material is subject to a considerable thermomechanical effect, which substantially changes not only the physical-mechanical properties of boundary layers, but also the topography of the workpiece surface and the chip. This greatly changes the emissivity of the surface to be measured. To take account of this phenomenon in the determination of the cutting temperature, the measuring system must be calibrated together with the measuring instruments for optically establishing the cutting temperature. This also concerned the temperature determination at the exterior surface of the chip in the accessible area of the primary cutting zone (s. Fig. 1 and Fig. 2).

The fundamentals for establishing the temperature in cutting processes with different methods have been described in detail, e.g. in studies by G. Barrow [52] and G. W. Burns with M. G. Scroger [53]. In principle, there are two fundamentally different measuring methods for determining the temperature: contact and contactless methods [54]. The contact methods can be divided into stationary and dynamic methods. In the case of stationary methods, different thermosensors are used for the measurements [40]. With the dynamic methods, the temperature is measured using the tool and the workpiece, which are electrically isolated from each other but in contact during the measurement. Various techniques are used to calibrate the thermosensors as well as the tool-workpiece pair (see e.g. [55], [56], [57], [58], [59]). The contact methods are rarely applied for temperature measurements due to the great inertia of the used sensors and the considerable difficulties in placing such measuring elements as close to the cutting zones as possible [60]. In the last years, fiber-optic two-color pyrometers have been used for establishing the cutting temperature [61]. The principle is based on double measurements of the surface emissivity at two different wavelengths in the infrared range. When assuming that the object to be measured is a grey body of which the emissivity is independent from the wavelength, it is possible to evaluate the temperature and the emissivity of the chip 
surface using this method. Several measurements of cutting temperatures were carried out with such a twocolor pyrometer [32], [62]. When the temperature was determined at the exterior surface of the chip, the surface to be measured was, however, not similar to the grey body and thus dependent on the wavelength [60]. In addition, it was very difficult or nearly impossible to orientate the measuring part of the glass fiber of the two-color pyrometer towards the measuring field. Measuring methods with pyrometers or thermographic cameras are better suited to measure the temperature at the exterior surface of the chip [60], [63], [64], [65]. The measuring system must be calibrated here with real test objects used in the experiments (exterior surface of a chip) as well as their surface properties. This method [60], [66] was used to calibrate the measuring system for the temperature determination. Fig. 3 shows the fundamental scheme for calibrating the measuring system. The pyrometer measured the temperature at the surface of the real chip during this calibration. This real chip was put on a heating unit and heated up to a set temperature using two heating elements. In addition to the pyrometer, the actual temperature in the heating unit and the chip was measured simultaneously using a calibrated thermosensor, type PT-100. Due to the signal of the actual temperature, a control signal was produced using the control program worked out in the environment of the LabVIEW software. Based on this signal, the power regulator, type $\mathrm{M} 028 \mathrm{~N}$, in the control unit created the desired voltage with which the heating elements were fed. Thus, the heating elements warmed up the heating unit with the chip to a temperature set in the control program. The PID controller (proportional-integral-derivative controller) integrated into the LabVIEW control program ensured that the set temperature of the heating unit with the chip could be kept reliably.

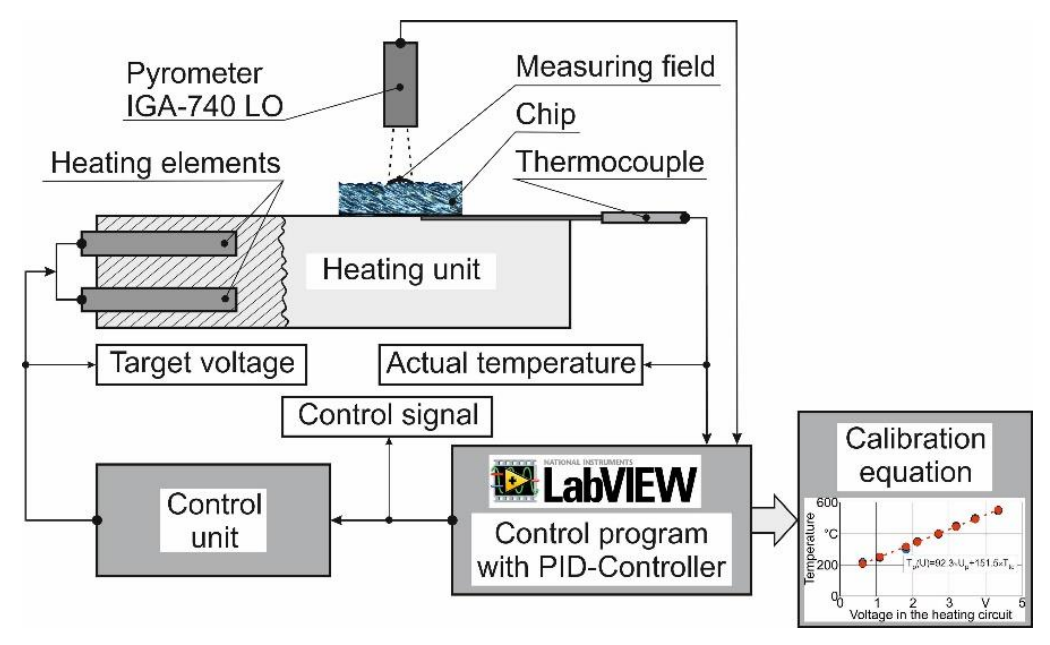

Fig. 3: Scheme for calibrating the measuring system.

By comparing the signal of the pyrometer with the temperature of the chip, it was possible to create a 
calibration equation using the LabVIEW program. Fig. 4 presents an example for the calibration equation regarding the temperature measurement at the exterior surface of the chip in the machining of AISI 1045 steel.

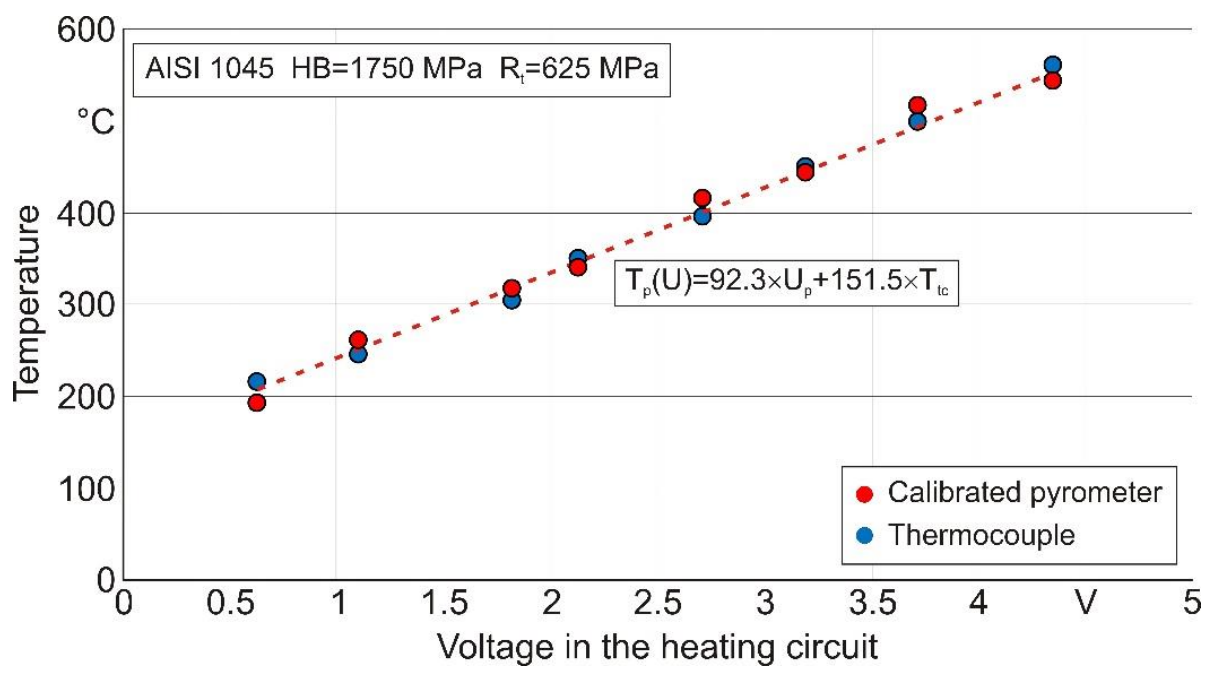

Fig. 4: Determination of the calibration equation.

This method of calibration using real chips obtained during experimental studies provided the possibility for eliminating uncertainty when measuring the temperature in the transition area from the primary cutting zone to the exterior surface of the chip.

\section{Experimental tests}

The experimental tests for establishing the temperature at the exterior surface of the chip (see Fig. 1) were carried out applying the cutting parameters listed in Table 1. As an example, Fig. 5 shows the temperatures at the exterior surface of the chip measured during the orthogonal cutting of three test materials: AISI 1045 (Fig. 5, a), AISI 4140 (Fig. 5, b) and Ti-1023 (Fig. 5, c).

The temperature development is described depending on the different values for the true final strain of the work material in the primary cutting zone and on the different Péclet numbers. It has to be noted here that the presented temperatures were interpolated to rounded values of true final strain. This was necessary in order to be able to compare the temperatures for different Péclet numbers.

The temperature at the exterior surface of the chip increased monotonously with rising true final strain. In the case of cutting processes with higher Péclet numbers, the temperature reached considerably greater values. The change in true final strain necessary for the experimental tests was obtained by correspondingly different values of tool orthogonal rake angle $\gamma$ and chip compression ratio $K_{a}$ (see Equation (2)). The different Péclet 
numbers were guaranteed by a change in cutting speed $V_{C}$ and undeformed chip thickness or depth of cut $a$ (see Equation (4)).

As expected, the temperature in the cutting of heat-treatable steel AISI 1045 was considerably lower than in the machining of AISI 4140 high-alloy steel for corresponding values of true final strain and the Péclet number. This difference was also caused amongst other things by the substantial difference in the hardness of the steel materials. Regarding the materials examined in this study, the highest temperature occurred in the cutting process of Ti-1023 titanium alloy. This could be attributed to the considerably greater values of the true ultimate strength $R_{t}$ and the hardness of the material. It was also not insignificant for the process of temperature development that the toughness was considerably greater than in the case of steel materials.

All tests carried out in this study with regard to the temperature at the exterior surface of the chip in the area of the primary cutting zone showed the same character as the results depicted as examples in Fig. 5 . These were used further for establishing the desired thermal properties of the work material.

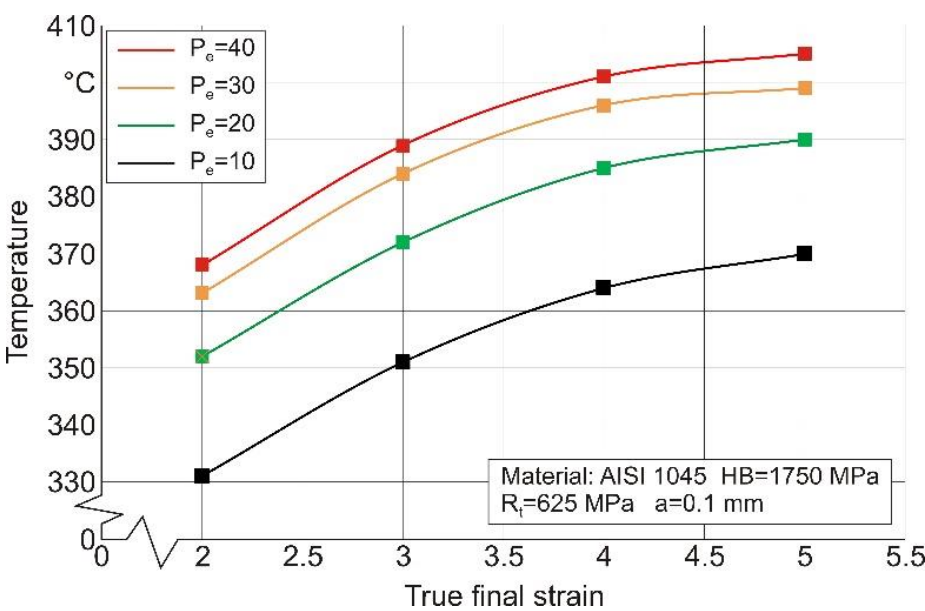

a)

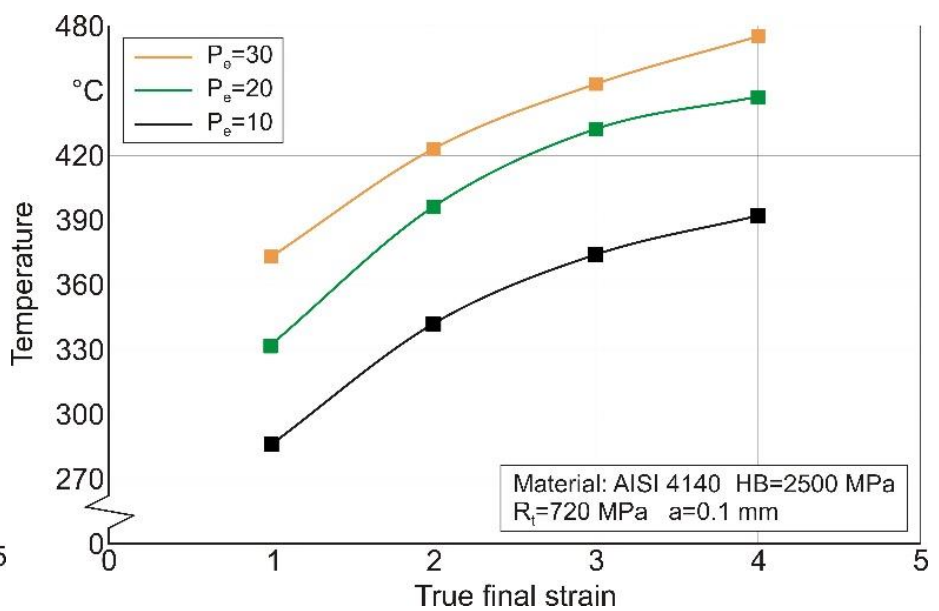

b)

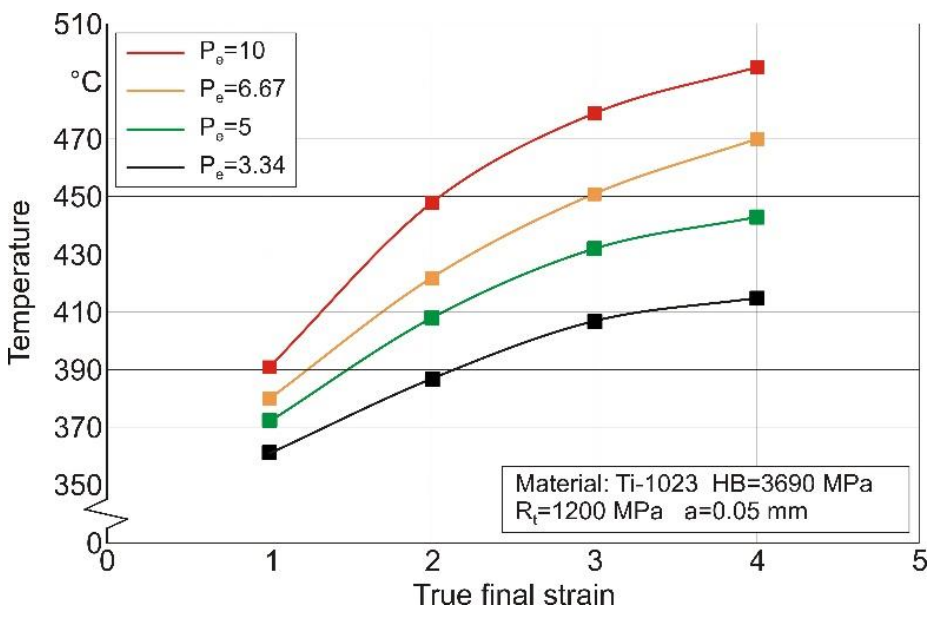

c)

Fig. 5: Temperature at the exterior surface of the chip. 


\section{Determination of thermal material properties}

The methodology described in Chapter 3 was used for calculating the coefficient of volumetric heat capacity $C_{V}$ or mass-specific heat capacity $C_{m}$ as well as the coefficient of thermal conductivity $\lambda$ of the work material. The coefficients were determined for all three calculation variants: due to the Johnson-Cook constitutive equation (JC), based on resultant forces established by experiment (MF) and using directly calculating the tangential stress (TS) in the primary cutting zone (s. Chapter 3).

The parameters of the Johnson-Cook constitutive equation were established for the examined materials using the method in [6] and listed in Table 2. These values of the parameters were used for calculating the thermal properties of the work material according to the first variant.

Table 2: Johnson-Cook constitutive equation parameters.

\begin{tabular}{|c|c|c|c|c|c|}
\hline Material & A [MPa] & B [MPa] & $\mathrm{n}[-]$ & $\mathrm{C}[-]$ & $\mathrm{m}[-]$ \\
\hline AISI 1045 & 612.1 & 475.9 & 0.2136 & 0.0181201 & 0.848 \\
\hline AISI 4140 & 632.3 & 546 & 0.1784 & 0.0175 & 1.46 \\
\hline Ti-1023 & 976.9 & 502.3 & 0.2214 & 0.02812 & 0.8 \\
\hline
\end{tabular}

Table 3 shows the dependences of the coefficient of mass-specific heat capacity $C_{m}$ and the coefficient of thermal conductivity $\lambda$ on different values of final strain $\varepsilon_{w}$ and calculation variants for the analyzed materials, using one value of the Péclet number and the depth of cut as an example. When comparing the presented dependences, it could be noted that both coefficients $C_{m}$ and $\lambda$ increase with growing true final strain $\varepsilon_{w}$. The final strain of the work material in the primary cutting zone during machining and the calculation variant affected the calculated values of both coefficients in fundamentally different ways. This effect also differed from material to material (s. Table 3). How much and in which way these influences had an effect differed with the change in cutting parameters, the chemical composition as well as the mechanical properties of the work material, the tool geometry and other cutting conditions. When analyzing the correlations between the thermal properties of the work material, which have to be established, and the above-mentioned process parameters, it appeared that they have a unique character in every single case. Hence, it would be hardly possible to generalize them. That would require calculating the thermal properties of the work material in every case to be conducted for the simulation. Regarding the completely structured analytical model for establishing these properties (see Chapter 3), the calculation method is suited well for the programming. 
Thus, the thermal properties required for simulating the cutting process could be calculated easily and reliably.

The question which calculation variant would be more suitable for establishing the thermal properties, should be answered based on the simulation results for the cutting processes. This is dealt with in the next chapter.

Table 3: Calculated values of the thermal properties $C_{m}$ and $\lambda$.

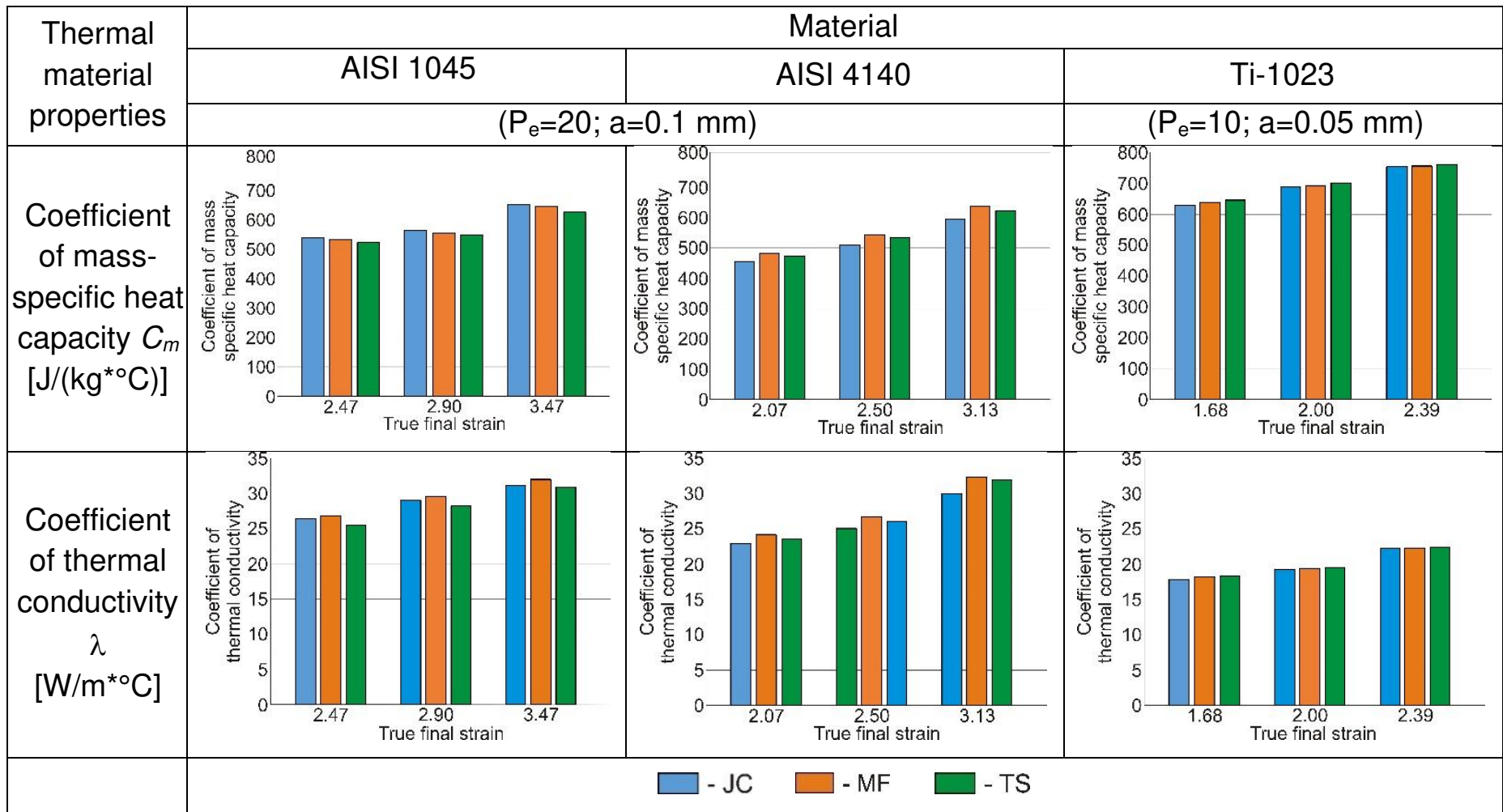

\section{Simulation of orthogonal cutting processes}

In order to verify the elaborated methodology for determining the thermal properties of the work material and to validate the suggested calculation variants, a FEM modeling and a subsequent simulation of the orthogonal cutting process were carried out. The FEM cutting model was developed in the environment of the commercial software DEFORM 2D/3D ${ }^{\mathrm{TM}}$ [67]. The simulation was based on the updated implicit Lagrangian formulation method. It was assumed for all models that the material of the workpiece was isotropic of the plastic type and the material of the tool was rigid. The material model of the three examined materials was based on the constitutive Johnson-Cook equation with the model parameters listed in Table 2. The fracture mechanism of the cutting process was modeled with the damage model by Cockcroft and Latham [68]. The critical elongation for AISI 1045 steel was $210 \mathrm{MPa}, 280 \mathrm{MPa}$ for AISI 4140 steel and 240 MPa for Ti-1023 titanium alloy respectively. These critical stresses were determined with the help of a design 
of experiments (DOE) analysis [6], [69]. The contact between tool and chip as well as between tool and workpiece was modeled with a hybrid friction model. The friction model was composed of a combination of the Coulomb model and a shear friction model. Regarding the modeling of the cutting processes for AISI 1045 and AISI 4140 steel, the Coulomb coefficient of friction was 0.15 and the plastic proportion of the shear friction model was 0.6 . Regarding the modeling of the friction process during the machining of Ti-1023 titanium alloy, the Coulomb coefficient of friction was 0.2 and the shear friction coefficient was 0.8 [6], [69]. Fig. 6 presents the meshed initial geometrical model with boundary conditions. The boundary conditions were determined by fixing the workpiece and the tool as well as by the input of the thermal conditions at the boundaries of the respective objects. The bottom of the workpiece was rigidly fixed in the X-, Y- and Zdirections. The rigid fixation of the tool at the back of its rake face in Z-direction prevented its meshing in this direction. The thermal initial conditions at room temperature $T_{r}$ were given at the bottom and the left-hand side of the workpiece as well as at the right-hand side and the top of the tool. The working motion of the tool at a cutting speed $V_{C}$ for guaranteeing the cutting process was given by the absolute motion in the negative X-direction.

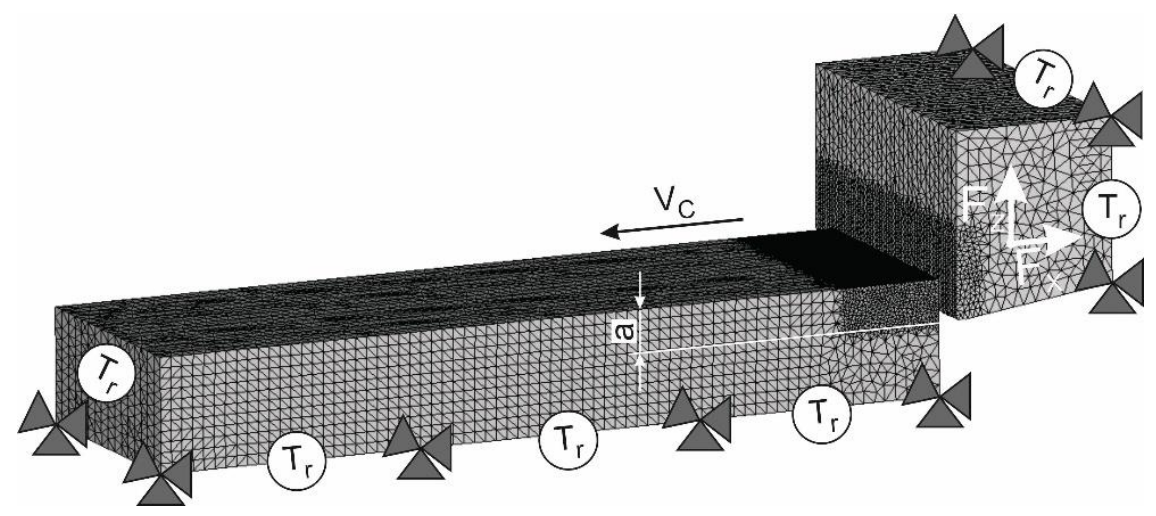

Fig. 6: Initial geometry and boundary conditions of the FEM cutting model.

The orthogonal cutting process of the examined materials was simulated with the FE model. Fig. 7 shows the development of the exemplary temperatures at the exterior surface of the chip, forming during machining. The experimental and simulated temperatures depending on the true final strain of the work material are one above the other here. The depicted results were selected as examples for the cutting parameters which were represented by the Péclet number of $P_{e}=20$ for AISI 1045 and AISI 4140 steel as well as $P_{e}=10$ for Ti-1023 
titanium alloy. The simulations were carried out with the values of the thermal material properties, established according to three variants: 1) due to the normal stress $\sigma_{t}$ calculated with the Johnson-Cook constitutive equation (JC), 2) based on the resultant forces $F_{X}$ and $F_{Z}$ determined by experiment (MF) and 3) through the direct calculation of tangential stress $\tau_{t}$ (TS). Experimental and simulated temperatures were determined at the same place, shown in the simulation pictures (s. Fig. 7, a, Fig. 7, b and Fig. 7, c).

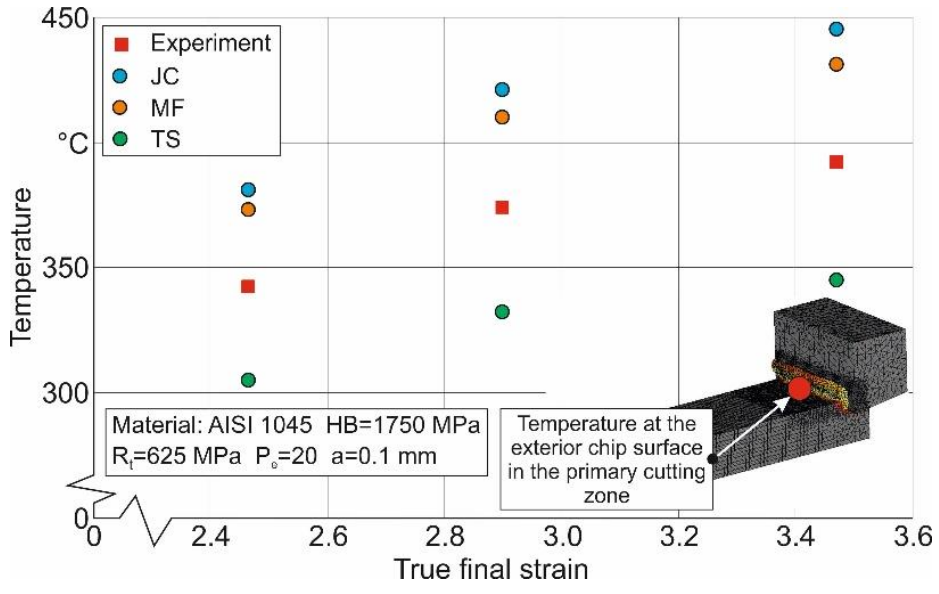

a)

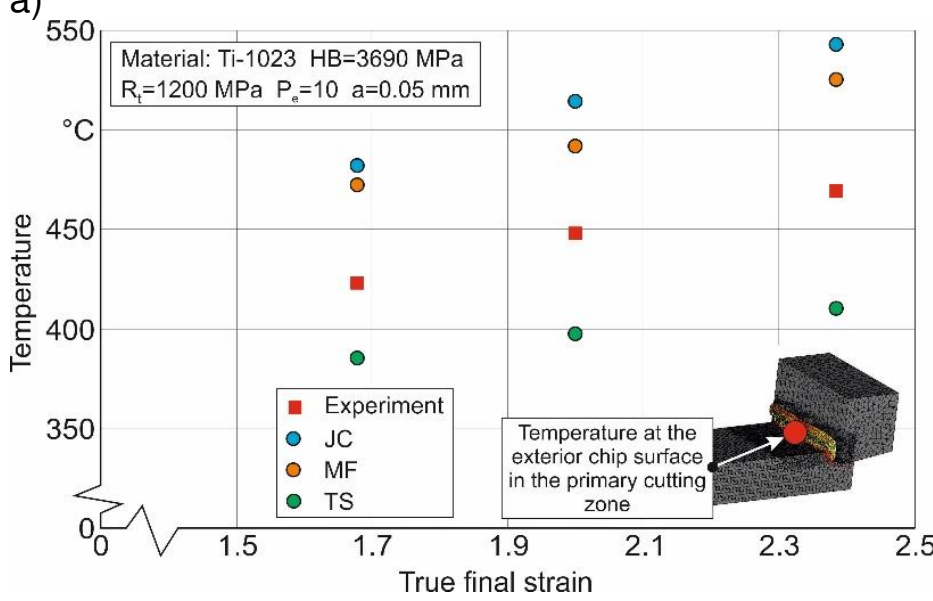

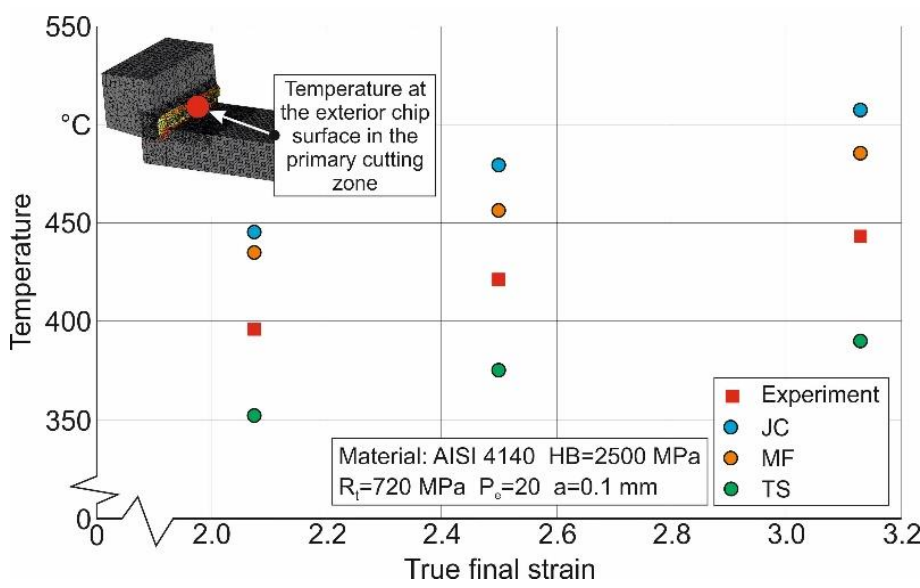

b)

c)

Fig. 7: Comparison of experimental and simulated temperatures.

The temperatures established by the experiment for these cutting parameters ranged from approx. $340{ }^{\circ} \mathrm{C}$ up to approx. $470^{\circ} \mathrm{C}$ for the three analyzed materials (s. Fig. 7). The temperatures at the exterior surface of the chip in the boundaries of the primary cutting zone were clearly higher in the cutting of the titanium alloy, as already shown in Fig. 5. The temperatures established by simulation showed a good agreement with the corresponding values determined by the experiment. The simulated cutting temperatures deviated from the experimental ones by approx. $7.5 \%$ to $14.4 \%$. For all three examined materials, the best agreement was 
achieved by those temperatures that were simulated based on the thermal properties calculated according to the second variant (MF) (see Fig. 7). That could be explained, as the experimentally determined components of the resultant forces were used in this case to establish the thermal properties of the material. The greatest deviation occurred in the third variant (TS) for calculating the thermal properties. Nonetheless, this variant also guaranteed a permissible deviation between the cutting temperatures established by experiment and by simulation.

Hence, the proposed methodology for determining the thermal properties of work materials offers a reasonably good agreement between the experimental and simulated values of cutting temperatures for the simulation of cutting processes.

\section{Conclusion}

The simulation of heat flows in the modeling of cutting processes depends considerably on the thermal properties of the work materials. During cutting, the work material is subject to a complex state of stressstrain, greatly influencing its thermomechanical properties. Hence, in order to simulate the machining processes of materials, the thermal properties of materials have to be established under real cutting conditions for each special case.

A methodology was worked out to determine the thermal properties of work materials, particularly for the simulation of cutting processes. This methodology was based on analytical models for establishing the tangential stress in the primary cutting zone. By means of this stress and the cutting temperature, which could be determined either by experiment or by analysis, thermal properties of the work materials were calculated, namely the coefficient of volumetric heat capacity $C_{V}$ or mass-specific heat capacity $C_{m}$ as well as the coefficient of thermal conductivity $\lambda$. Three variants were applied to establish the tangential stress: due to the normal stress $\sigma_{t}$, calculated with the Johnson-Cook constitutive equation; based on the resultant forces $F_{X}$ and $F_{Z}$ determined by experiment; and by the direct calculation of the tangential stress $\tau_{t}$. The calculations were carried out with the software-aided algorithm.

The thermal properties were established using the examples of three different materials: AISI 1045 steel, AISI 4140 steel and Ti-1023 titanium alloy (Ti10V2Fe3Al). For that purpose, a series of experimental tests were performed with regard to resultant forces and cutting temperatures for various cutting parameters and values of the true final strain of the work material, which were guaranteed by different tool geometries. By 
using the conducted experiments, it was possible to calculate the thermal properties of the work materials according to the three variants of the methodology developed for the whole range of cutting parameter variation and true final strain of the materials. Placing the calculated thermal properties one above the other illustrated a clear increase of these properties with rising Péclet number and true final strain of the work material. The dependence had an essentially generalized character, yet showed no clear correlation. Correspondingly, the thermal properties of the work material must be calculated separately in every single case.

The quality concerning the determination of the thermal material properties was assessed by comparing the cutting temperatures determined by experiment and simulation. To simulate the kinetic and thermal cutting characteristics, an FE model of orthogonal cutting processes was worked out, establishing the thermal properties of materials with the methodology developed. The comparison of temperatures showed a reasonably good agreement. The experimental temperature values differed from the simulated ones by approx. $7.5 \%$ to $14.4 \%$. The lowest deviation was achieved here with the calculation of thermal properties using the experimentally determined components of the resultant forces.

Hence, it is legitimate to claim that the methodology developed for establishing the thermal properties of work materials can be successfully applied to model the cutting processes of these materials.

\section{Acknowledgments}

The authors would like to thank the German Research Foundation (DFG) for their support, which is highly appreciated.

\section{Declarations}

\section{Funding}

This research was supported in part by the German Research Foundation (DFG) HE 1656/153-2 "Development of a Concept for Determining the Mechanical Properties of the Cutting Material in Machining".

\section{Competing interests}

The authors declare that they have no known competing financial interests or personal relationships that could have appeared to influence the work reported in this paper. 


\section{Availability of data and material}

The data sets supporting the results of this article are included within the article.

Code availability

Not applicable.

\section{Authors' contributions}

Michael Storchak: Conceptualization, Methodology, Formal analysis, Software, Validation, Investigation, Data Curation, Visualization, Writing - Original Draft, Review \& Editing;

Thomas Stehle: Funding acquisition, Project administration.

Hans-Christian Möhring: Writing - Review \& Editing, Supervision, Project administration;

\section{Ethics approval}

Not applicable.

\section{Consent to participate}

Not applicable.

\section{Consent for publication}

All of the authors have informed us of their consent to the publication of the paper.

\section{References}

[1] Ivester, R. W.; Kennedy, M.; Davies, M.; Stevenson, R.; Thiele, J.; Furness, R.; Athavale, S.: Assessment of Machining Models: Progress Report. Machining Science and Technology, 2000, Vol. 4, Issue 3, pp. 511-538. https://doi.org/10.1080/10940340008945720.

[2] Arrazola, P.J.; Özel, T.; Umbrello, D.; Davies, M.; Jawahir, I.: Recent advances in modelling of metal machining processes. CIRP Ann. Manuf. Technol. 2013, Vol. 62, pp. 695-718. https://doi.org/10.1016/j.cirp.2013.05.006.

[3] Mourtzis D.; Doukas M.; Bernidaki D. Simulation in Manufacturing: Review and Challenges. Procedia CIRP, 2014, Vol. 25, 213-229. https://doi.org/10.1016/i.procir.2014.10.032.

[4] Grzesik, W.: Modelling of heat generation and transfer in metal cutting: a short review. Journal of Machine Engineering, 2020, Vol. 20, No. 1, pp. 24 - 33. https://doi.org/10.36897/jme/117814.

[5] Özel, T.; Zeren, E. A.: A Methodology to Determine Work Material Flow Stress and Tool-Chip Interfacial Friction Properties by Using Analysis of Machining. ASME J. Manuf. Sci. Eng., 2006, Vol. 128, Issue 1, pp. 119 - 129. https://doi.org/10.1115/1.2118767.

[6] Storchak, M.; Rupp, P.; Möhring, H.-C.; Stehle, T. Determination of Johnson-Cook Constitutive Parameters for Cutting Simulations. Metals 2019, Vol. 9, Issue 4, 473. https://doi.org/10.3390/met9040473.

[7] Melkote, S. N. et. al.: Advances in material and friction data for modeling of metal machining. CIRP Annals, 2017, Vol. 66, Issue 2, pp. 731 - 754. https://doi.org/10.1016/i.cirp.2017.05.002.

[8] Buchkremer, S.; Schoop, J.: A mechanics-based predictive model for chip breaking in metal machining and its validation. CIRP Annals, 2016, Vol. 65, Issue 1, pp. 69 - 72. https://doi.org/10.1016/i.cirp.2016.04.089.

[9] Hu, C. et. al.: Cutting temperature prediction in negative-rake-angle machining with chamfered insert based on a modified slip filed model. International Journal of Mechanical Sciences, 2020, Vol. 167, 105273. https://doi.org/10.1016/j.ijmecsci.2019.105273.

[10] Kumar, A.; Bhardwaj, R.; Joshi, S. S.: Thermal modeling of drilling process in titanium alloy (Ti-6Al-4V). Machining Science and Technology, 2020, Vol. 24, Issue 3, pp. 341 - 365. https://doi.org/10.1080/10910344.2019.1698607. 
[11] Osorio-Pinzon, J. C.; Abolghasem, S.; Casas-Rodriguez, J. P.: Predicting the Johnson-Cook constitutive model constants using temperature rise distribution in plane strain machining. International Journal of Advanced Manufacturing Technology, 2019, Vol. 105, Issue 1-4, pp. 279 - 294. https://doi.org/10.1007/s00170-019-04225$\underline{9}$.

[12] Tu, L. et. al.: Temperature distribution of cubic boron nitride-coated cutting tools by finite element analysis. International Journal of Advanced Manufacturing Technology, 2019, Vol. 105, Issue 7-8, pp. 3197-3207. https://doi.org/10.1007/s00170-019-04498-0.

[13] Davies, M. A.; Ueda, T.; M'Saoubi, R.; Mullany, B.; Cooke, A. L.: On the Measurement of Temperature in Material Removal Processes. CIRP Annals, 2007, Vol. 56, Issue 2, pp. 581 - 604. https://doi.org/10.1016/i.cirp.2007.10.009.

[14] Kronenberg, M.: Machining science and application: theory and practice for operation and development of machining processes. Oxford: Pergamon Pr. 1966, 410 p.

[15] Mills, K. C.: Recommended values of thermophysical properties for selected commercial alloys. Woodhead Published Lim., Cambridge England, 2002, 244 p.

[16] Craviero, H. D. et. al.: Review of the high temperature mechanical and thermal properties of the steel used in cold formed steel structures - The case of the S280 Gd+Z steel. Thin-Walled Structures, 2016, Vol. 98, pp. 154 - 168. https://doi.org/10.1016/j.tws.2015.06.002.

[17] Franssen, J. M.; Real, P. V.: Fire Design of Steel Structures. $2^{\text {nd }}$ Edition, Wiley Ernst \& Sohn, Berlin, 2015, 450 p.

[18] Fang, H.; Wong, W. B.; Bai, Y.: Use of kinetic model for thermal properties of steel at high temperatures. Australian Journal of Civil Engineering, 2015, Vol. 13, No. 1, pp. 40 - 47. https://doi.org/10.1080/14488353.2015.1092637.

[19] Wielgosz, E.; Kargul, T.; Falkus, J.: Comparison of experimental and numerically calculated thermal properties of steels. Conference "Metal 2014", Brno, Chech Republic, May $2^{\text {st }}-23^{\text {rd }}, 2014$.

[20] Özel, T.; Altan, T. Determination of workpiece stress and friction at the chip-tool contact for high speed cutting. Journal of Machine Tools \& Manufacture, 2000, 40, 133-152. https://doi.org/10.1016/S0890-6955(99)00051-6.

[21] Abukhshim, M. A.; Mativenga, P. T.; Sheikh, M. A.: Heat generation and temperature prediction in metal cutting: A review and implications for high speed machining. International Journal of Machine Tools \& Manufacture, 2006, Vol. 46, Issue 7-8, pp. 782 - 800. https://doi.org/10.1016/i.ijmachtools.2005.07.024.

[22] Biermann, D.; Hollmann, F.: Thermal Effects in Complex Machining Processes. Final Report of the DFG Priority Programme 1480. Springer, 2018. https://doi.org/10.1007/978-3-319-57120-1.

[23] Ebrahimi, S. M.; Araee, A.; Hadad, M.: Investigation of the effects of constitutive law on numerical analysis of turning processes to predict the chip morphology, tool temperature, and cutting force. International Journal of Advance Manufacturing Technology, 2019, Vol. 105, Issue 10, pp. 4245 - 4264. https://doi.org/10.1007/s00170019-04502-7.

[24] Hu, C.; Zhuang, K.; Weng, J.; Pu, D.: Three-dimensional analytical modeling of cutting temperature for round insert considering semi-infinite boundary and non-uniform heat partition. International Journal of Mechanical Sciences, 2019, Vol. 155, pp. 536 - 553. https://doi.org/10.1016/j.ijmecsci.2019.03.019.

[25] Chen, Y.; Li, H.; Wang, J.: Further Development of Oxley's Predictive Force Model for Orthogonal Cutting. Mach. Sci. Technol., 2015, Vol. 19, Issue 1, pp. 86-111. https://doi.org/10.1080/10910344.2014.991026.

[26] Crichigno Filho, J. M.: Applying extended Oxley's machining theory and particle swarm optimization to model machining forces. The International Journal of Advanced Manufacturing Technology, 2017, Vol. 89, Issue 1-4, pp. 1127 - 1136. https://doi.org/10.1007/s00170-016-9155-6.

[27] Huang, Y.; Liang, S. Y.: Cutting forces modeling considering the effect of tool thermal property-application to CBN hard turning. International Journal of Machine Tools \& Manufacture, 2003, Vol. 43, Issue 3, pp. $307-315$. https://doi.org/10.1016/S0890-6955(02)00185-2.

[28] Choi, I.-R; Chung, K.-S.; Kim, D.-H.: Thermal and mechanical properties of high-strength structural steel HSA800 at elevated temperatures. Materials and Design, 2014, Vol. 63, pp. 544 - 551. https://doi.org/10.1016/j.matdes.2014.06.035.

[29] Chen, Z.; Lu, J.; Liu, H.; Liao, X.: Experimental study on the post-fire mechanical properties of high-strength steel tie rods. Journal of Constructional Steel Research, 2016, Vol. 121, pp. 311 - 329. https://doi.org/10.1016/j.jcsr.2016.03.004.

[30] Gardner, L. et. al. Elevated temperature material properties of stainless steel reinforced bar. Construction and Building Materials, 2016, Vol. 114, pp. 977 - 997. https://doi.org/10.1016/i.conbuildmat.2016.04.009.

[31] Fan, S. et. al. Experimental investigation of austenitic stainless steel material at elevated temperatures. Construction and Building Materials, 2017, Vol. 155, pp. $267 \quad$ - 285. 
https://doi.org/10.1016/i.conbuildmat.2017.08.047.

[32] Díaz-Álvarez, J.; Tapetado, A.; Vázquez, C.; Miguélez, H.: Temperature Measurement and Numerical Prediction in Machining Inconel 718. Sensors, 2017, Vol. 17, Issue 7, 1531. https://doi.org/10.3390/s17071531.

[33] Michna, J.: Numerical and experimental investigation of cutting-induced microstructure transformation and modeling of the thermo-mechanical load collective when drilling 42CrMo4. Dissertation, Institute for Technology, Karlsruhe, 2014, $196 \mathrm{p}$.

[34] Attanasio, A.; Umbrello, D.: Abrasive and Diffusive Tool Wear FEM Simulation. International Journal of Material Forming, 2009, Vol. 2, Issue 1, pp. 543 - 546. https://doi.org/10.1007/s12289-009-0475-z.

[35] Oxley, P.L.B. Mechanics of Machining. An Analytical Approach to Assessing Machinability. Ellis Horwood: Chichester, UK, 1989; 242 p. https://doi.org/10.1115/1.2888318.

[36] Zorev, N.N. Metal cutting mechanics. Pergamon Press GmbH: Frankfurt am Main, Germany, 1966; 526 p.

[37] Heisel, U.; Kushner, V.; Storchak, M.: Effect of machining conditions on specific tangential forces. Production Engineering, 2012, Vol. 6, Issue 6, pp. 621 - 629. https://doi.org/10.1007/s11740-012-0417-3.

[38] Kushner, V.; Storchak, M.: Modelling the Material Resistance to Cutting. International Journal of Mechanical Sciences, 2017, Vol. 126, pp. 44 - 54. https://doi.org/10.1016/j.ijmecsci.2017.03.024.

[39] Möhring, H.-C.; Kushner, V.; Storchak, M.; Stehle, T. Temperature calculation in cutting zones. CIRP Annals, 2018, Vol. 67, Issue 1, pp. 61 - 64. https://doi.org/10.1016/i.cirp.2018.03.009.

[40] Heisel, U.; Storchak, M.; Eberhard, P.; Gaugele, T.: Experimental studies for verification of thermal effects in cutting. Production Engineering, 2011, Vol. 5, Issue 5, pp. 507 - 515. https://doi.org/10.1007/s11740-011-0312$\underline{3}$.

[41] Kushner, V.; Storchak, M. Determining mechanical characteristics of material resistance to deformation in machining. Production Engineering, 2014, Vol. 8, Issue 5, pp.: 679-688. https://doi.org/10.1007/s11740-0140573-8.

[42] Chao, B. T.; and Trigger, K. J.: Temperature Distribution at Tool-Chip and Tool-Work Interface in Metal Cutting. Trans. ASME, 1958, Vol. 80, pp. $311-320$.

[43] Grzesik, W.: Determination of temperature distribution in the cutting zone using hybrid analytical-FEM technique. Int. Journal of Machine Tools and Manufacture, 2006, Vol. 46, Issue 6, pp. 651- 658. https://doi.org/10.1016/i.ijmachtools.2005.07.009.

[44] Heisel, U.; Storchak, M.; Krivoruchko, D.: Thermal effects in orthogonal cutting. Production Engineering, 2013, Vol. 7, Issue 2, pp. 203-211. https://doi.org/10.1007/s11740-013-0451-9.

[45] Johnson, G.R.; Cook, W.H. A constitutive model and data for metals subjected to large strains, high strain and high temperatures. In Proceedings of the 7th International Symposium on Ballistics, The Hague, The Netherlands, 19-21 April 1983, pp. 541-547.

[46] Adibi-Sedeh, A.H.; Madhavan, V.; Bahr, B. Extension of Oxley's Analysis of Machining to Use Different Material Models. Journal of Manufacturing Science and Engineering 2003, Vol. 125, Issue 4, pp. 656-666. https://doi.org/10.1115/1.1617287.

[47] Lalwani, D.I.; Mehta, N.K.; Jain, P.K. Extension of Oxley's predictive machining theory for Johnson-and Cook flow stress model. J. Mater. Process. Technol. 2009, Vol. 209, Issue 12-13, pp. 5305-5312. https://doi.org/10.1016/i.jmatprotec.2009.03.020.

[48] Xiong, L.; Wang, J.; Gan, Y.; Li, B.; Fang, N. Improvement of algorithm and prediction precision of an extended Oxley's theoretical model. Int. J. Adv. Manuf. Technol. 2015, Vol. 77, pp. 1-13. https://doi.org/10.1007/s00170014-6361-y.

[49] Laakso, S. V. A.; Niemi, E.: Modified Johnson-Cook flow stress model with thermal softening damping for finite element modeling of cutting. Journal of Engineering Manufacture, 2016, Vol. 230, Issue 2, pp. $241-253$. https://doi.org/10.1177/0954405415619873.

[50] Calamaz, M.; Coupard, D.; Girot, F.: A new material model for 2D numerical simulation of serrated formation when machining titanium alloy Ti-6Al-4V. Int. J. of Machine Tools and Manufacture, 2008, Vol. 48, Issue 3-4, pp. 275 - 288. https://doi.org/10.1016/j.ijmachtools.2007.10.014.

[51] Denguir, L. A.; Outeiro, J. C.; Fromentin, G.; Vignal, V.; Besnard, R.: Orthogonal cutting simulation of OFHC copper using a new constitutive model considering the state of stress and the microstructure effects. Procedia CIRP, 2016, Vol. 46, pp. 238 - 241. https://doi.org/10.1016/i.procir.2016.03.208.

[52] Barrow, G.: A review of experimental and theoretical techniques for assessing cutting temperatures. CIRP Annals, 1973, Vol. 22, No. 2, pp.: 203-211.

[53] Burns, G. W.; Scroger, M. G.: The Calibration of Thermocouples and Thermocouple Materials. National Institute of Standards and Technology, 1989, $201 \mathrm{p}$. 
[54] Kus, A., Isik Y., Cakir, M. C.; Coşkun, S.; Özdemir, K.: Thermocouple and Infrared Sensor-Based Measurement of Temperature Distribution in Metal Cutting. Sensors, 2015, Vol. 15, Issue 1, pp. 1274 - 1291. https://doi.org/10.3390/s150101274.

[55] Cui, Y.; Yang, D.; Jia, Y.; Zeng, Q.; Sun, B.: Dynamic Calibration of the Cutting Temperature Sensor of NiCr/NiSi Thin-film Thermocouple. Chinese Journal of Mechanical Engineering, 2011, Vol. 24, No. 1, pp. 73 - 77. http://dx.doi.org/10.3901/CJME.2011.01.073.

[56] Dhar, N. R.; Islam, S.; Kamruzzaman, M.; Ahmed, T.: The Calibration of Tool-Work Thermocouple in Turning Steels. Conference Modeling, Simulation and Control of Engineering Systems, 2005, pp. 459 - 466.

[57] Kaminise, A. K.; Guimarães, J.; Bacci da Silva, M.: Development of a tool-work thermocouple calibration system with physical compensation to study the influence of tool-holder material on cutting temperature in machining. International Journal of Advanced Manufacturing Technology, 2014, Vol. 73, Issue 5 - 8, pp. 735 - 747. https://doi.org/10.1007/s00170-014-5898-0.

[58] Nedić, B. P.; Erić, M. D.: Cutting Temperature Measurement and Material Machinability. Thermal Science, 2014, Vol. 18, Issue 1, pp. 259 - 268. https://doi.org/10.2298/TSCI120719003N.

[59] Noriega, M.; Ramírez, R.; López, R.; Vaca, M.; Morales, J.; Terres, H.; Lizardi, A.; Chávez, S.: Thermocouples calibration and analysis of the influence of the length of the sensor coating. Journal of Physics: Conference Series 582, 2015, 012029, pp. 1 - 6. https://doi.org/10.1088/1742-6596/582/1/012029.

[60] Sutter, G.; Ranc, N.: Temperature fields in a chip during high-speed orthogonal cutting - An experimental investigation. Int. Journal of Machine Tools \& Manufacture, 2007, Vol. 47, Issue 10, pp. 1507 - 1517. https://doi.org/10.1016/j.ijmachtools.2006.11.012.

[61] Muller, B.: Temperature measurements with a fibre-optic two-colour pyrometer. In: H. Schulz (Ed.), Scientific Fundamentals of High Speed Cutting, Carl Hanser Verlag, München, 2001, pp.: 181-186. https://publications.rwth-aachen.de/record/87014.

[62] Tapetado, A. et. al.: Two-Color Pyrometer for Process Temperature Measurement During Machining. Journal of Lightwave Technology, 2016, Vol. 34, No. 4, pp.: 1380-1386. https://doi.org/10.1109/JLT.2015.2513158.

[63] Sutter, G. et. al.: An experimental technique for the measurement of temperature fields for the orthogonal cutting in high speed. International Journal of Machine Tools and Manufacture, 2003, Vol. 43, Issue 7, pp.: 671-678. https://doi.org/10.1016/S0890-6955(03)00037-3.

[64] Lis, K.; Kosmol, J.: Temperature Monitoring of the Drilling Process Using Thermovision Method. 12th International Research/Expert Conference "Trends in the Development of Machinery and Associated Technology" TMT 2008, Istanbul, Turkey, 26-30 August, 2008, pp. 113 - 116.

[65] Ranc, N.; Pina, V.; Sutter, G.; Philippon, S.: Temperature measurement by visible pyrometry: orthogonal cutting application. Journal of Heat Transfer, American Society of Mechanical Engineers, 2004, Vol. 126, Issue 6, pp.931-936. https://doi.org/10.1115/1.1833361.

[66] Soler, D.; Aristimuño, P. X.; Saez-de-Buruaga, M.; Arrazola, P. J.: Determination of emissivity and temperature of tool rake face when cutting AISI 4140. Procedia Manufacturing, 2019, Vol. 41, pp. 304-311 https://doi.org/10.1016/j.promfg.2019.09.013.

[67] Deform-User Manual SFTC-Deform V12.0, Columbus (OH), USA, 2019.

[68] Cockcroft, M. G.; Latham, D. J.: Ductility and workability of metals. Journal of the Institute of Metals, 1968, vol. 96, pp. 33-39.

[69] Storchak, M.; Jiang, L.; Xu, Y.; Li, X. FEM Modelling for the Cutting Process of the Titanium Alloy Ti10V2Fe3Al. Production Engineering, 2016, Vol. 10, pp. 509-517. https://doi.org/10.1007/s11740-016-0689-0. 


\section{Figures}

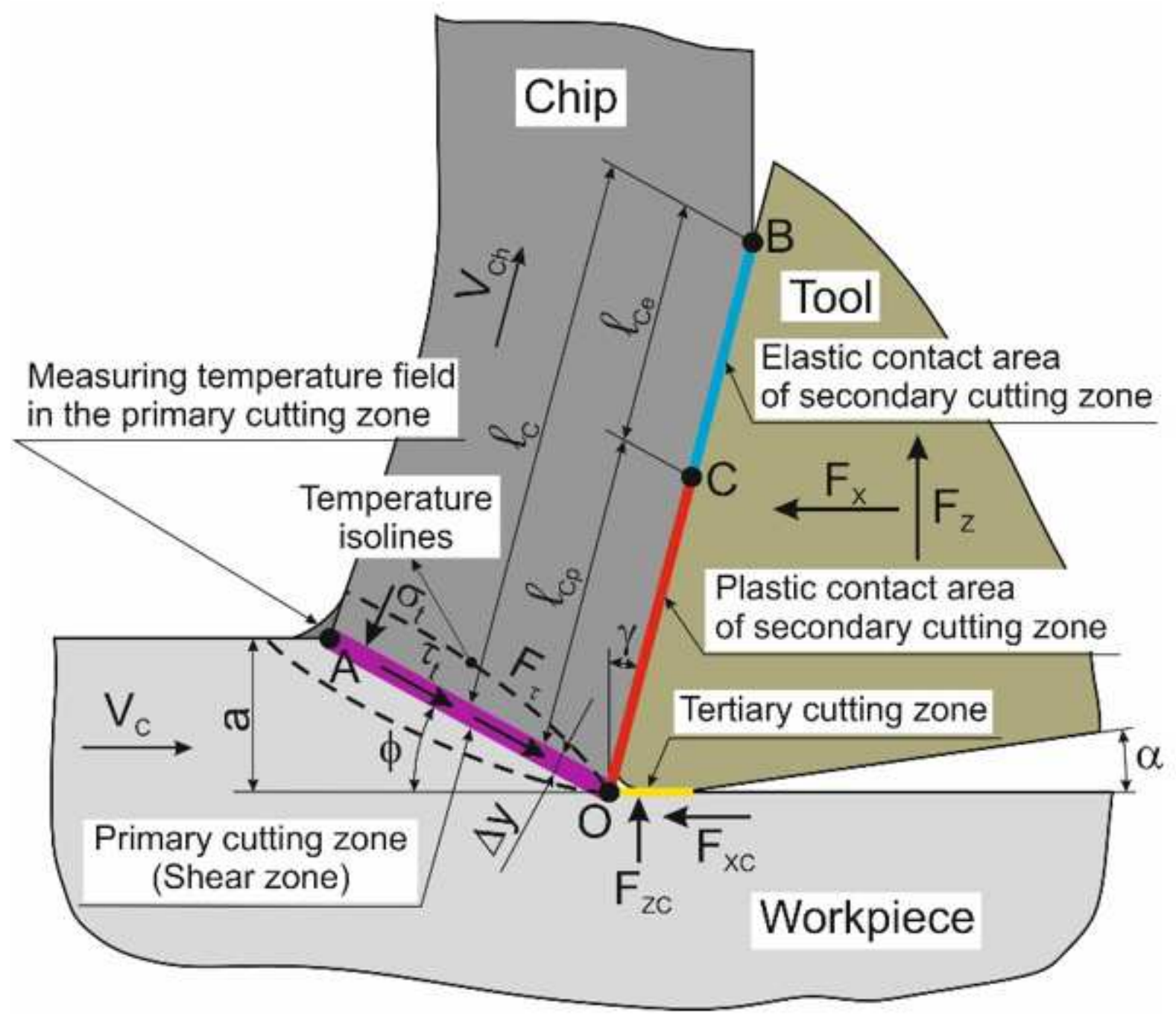

Figure 1

Layout of cutting zones. 


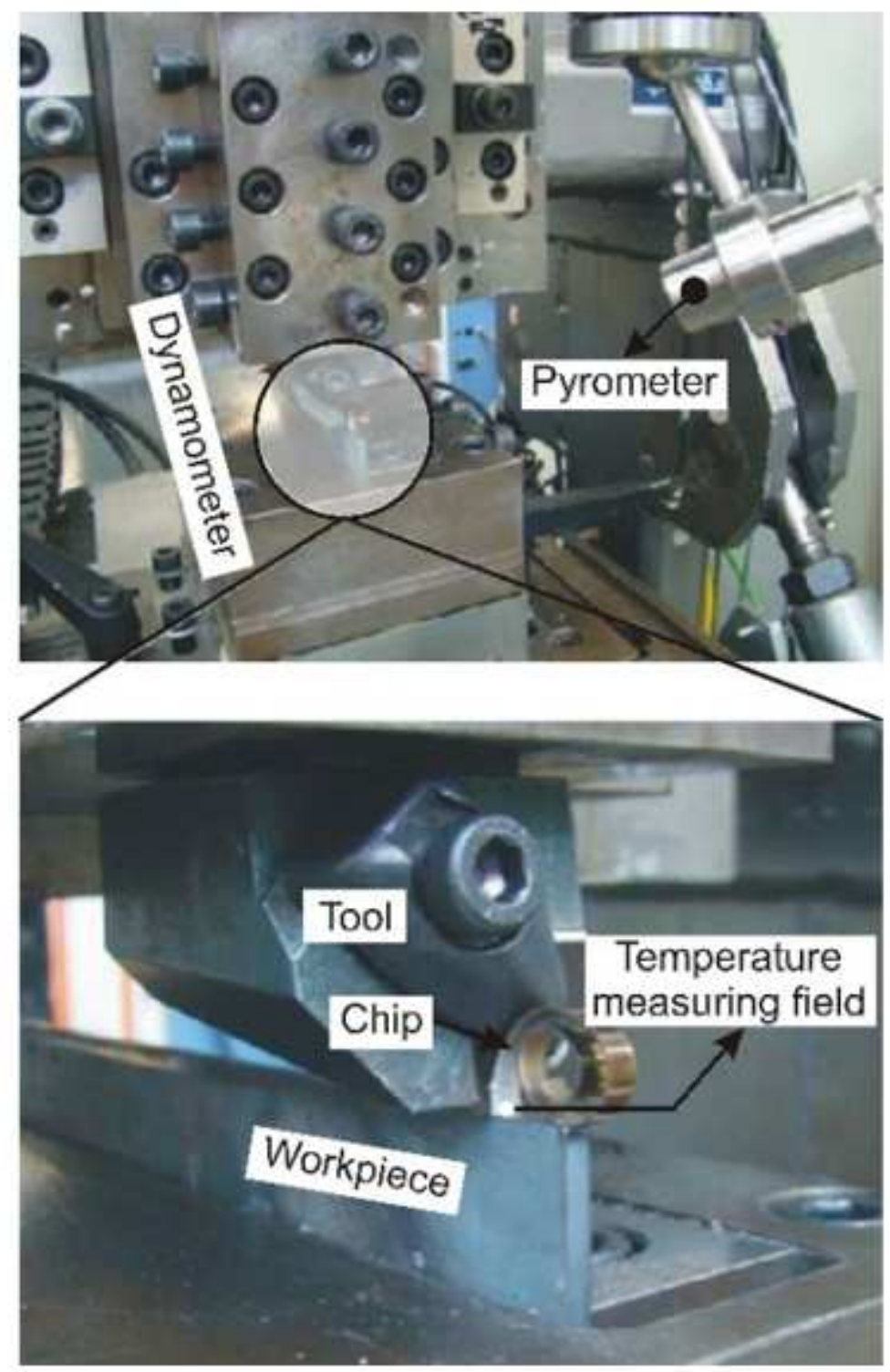

Figure 2

Experimental set-up for temperature measurement [44]. 


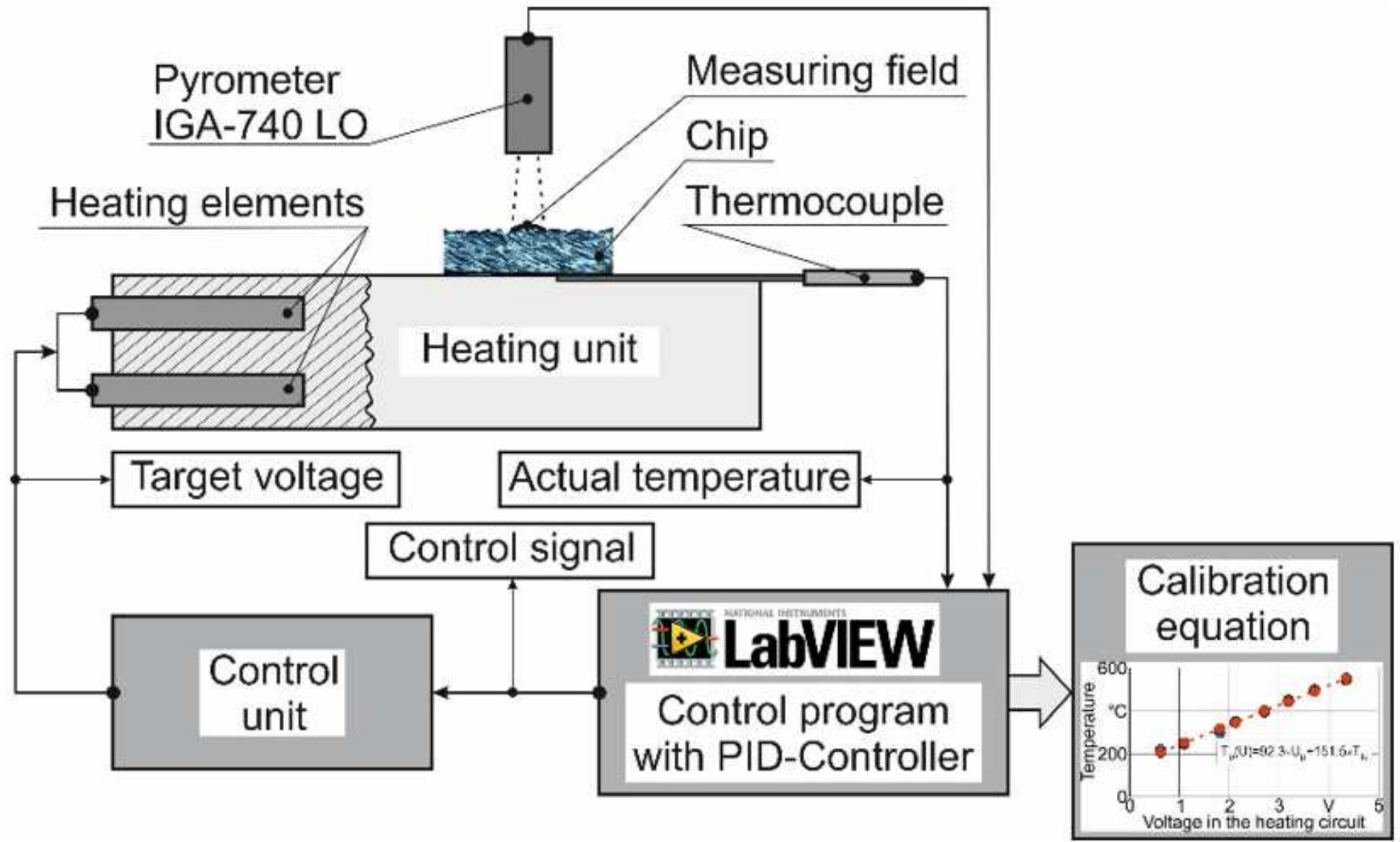

Figure 3

Scheme for calibrating the measuring system. 


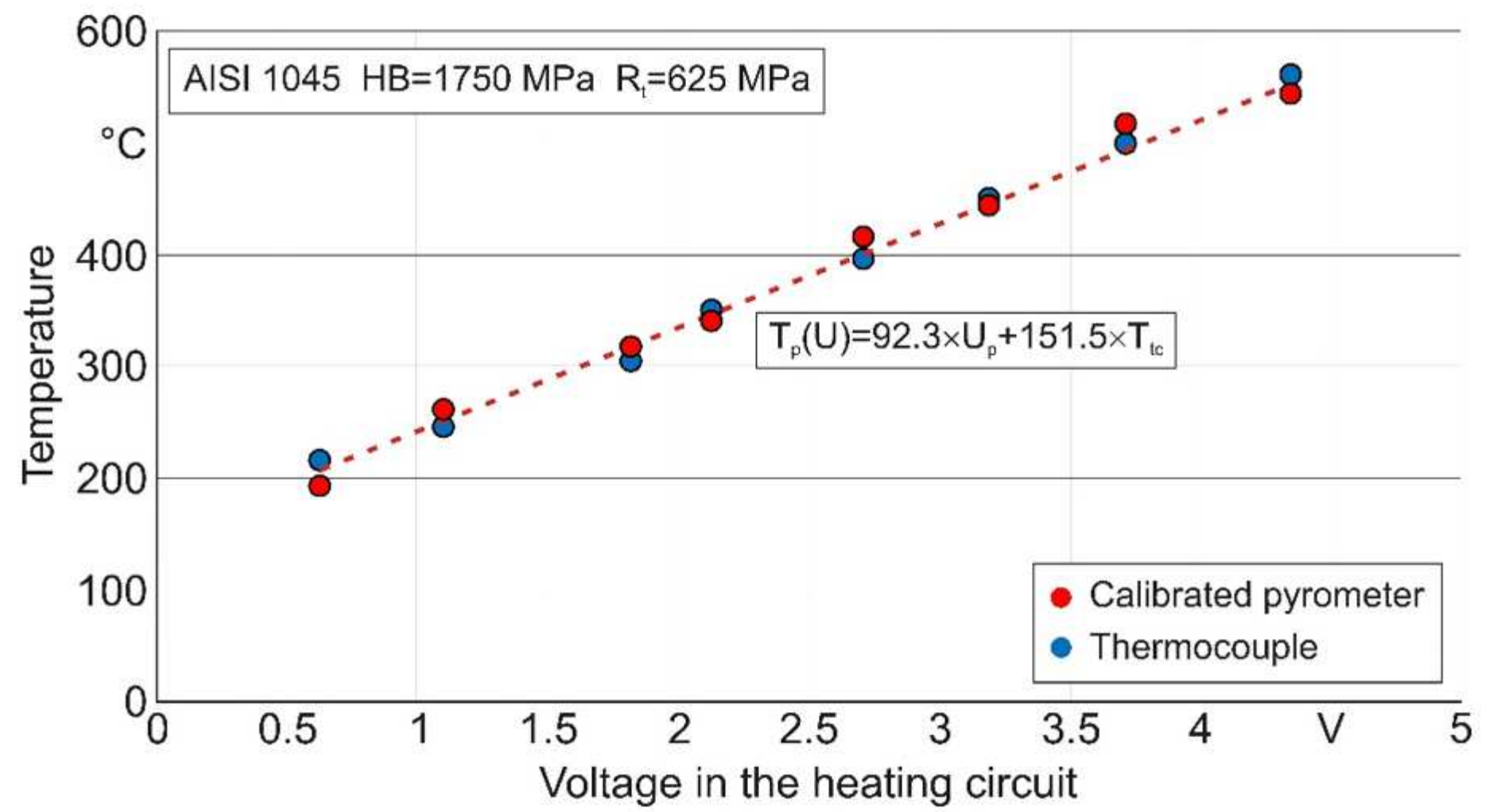

Figure 4

Determination of the calibration equation. 


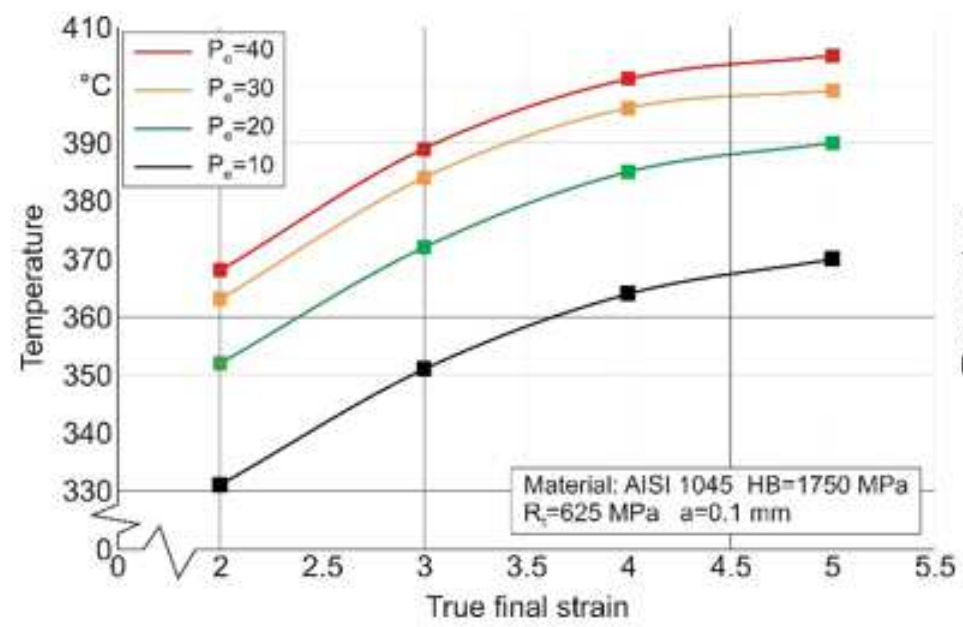

a)

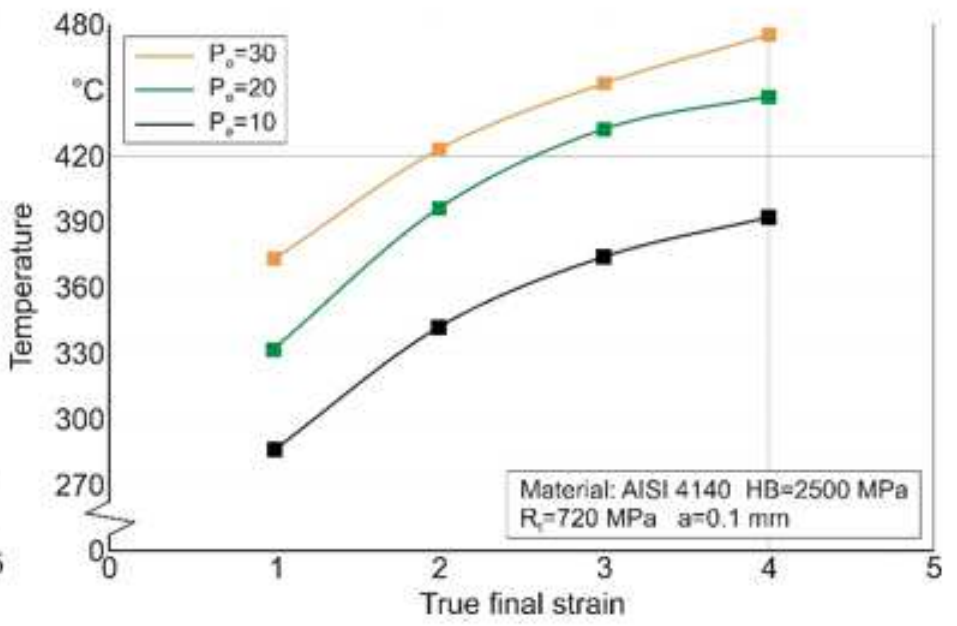

b)

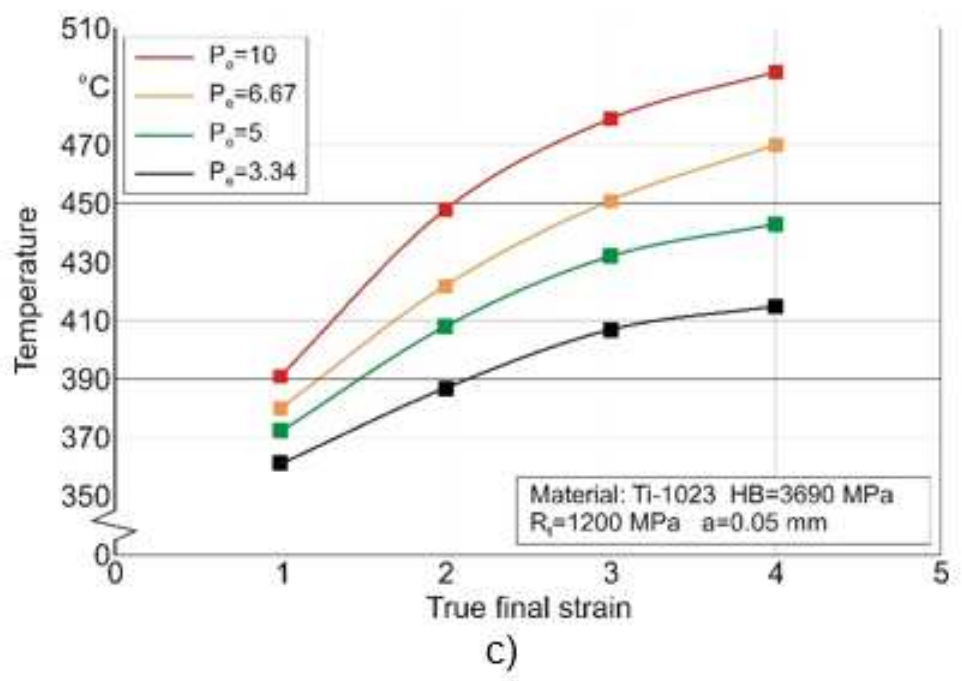

Figure 5

Temperature at the exterior surface of the chip. 


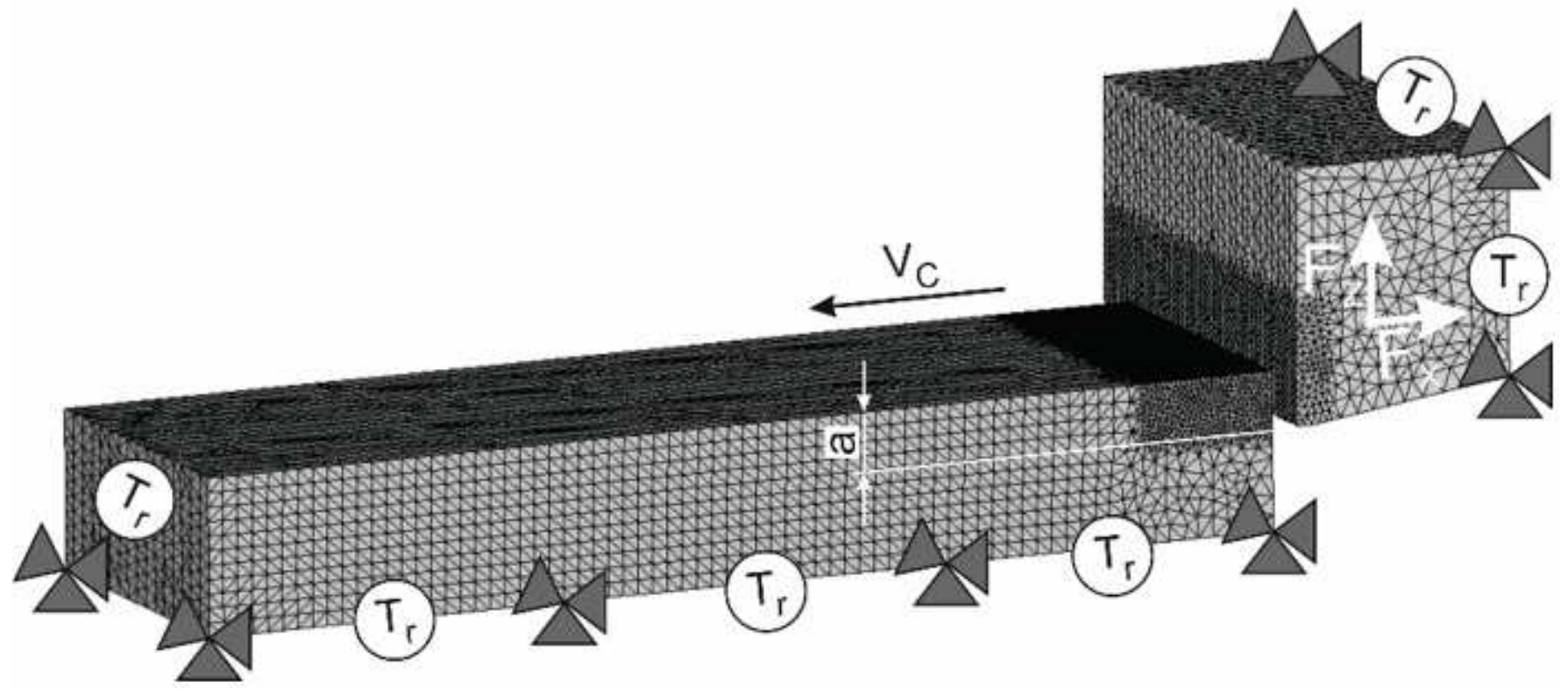

Figure 6

Initial geometry and boundary conditions of the FEM cutting model. 

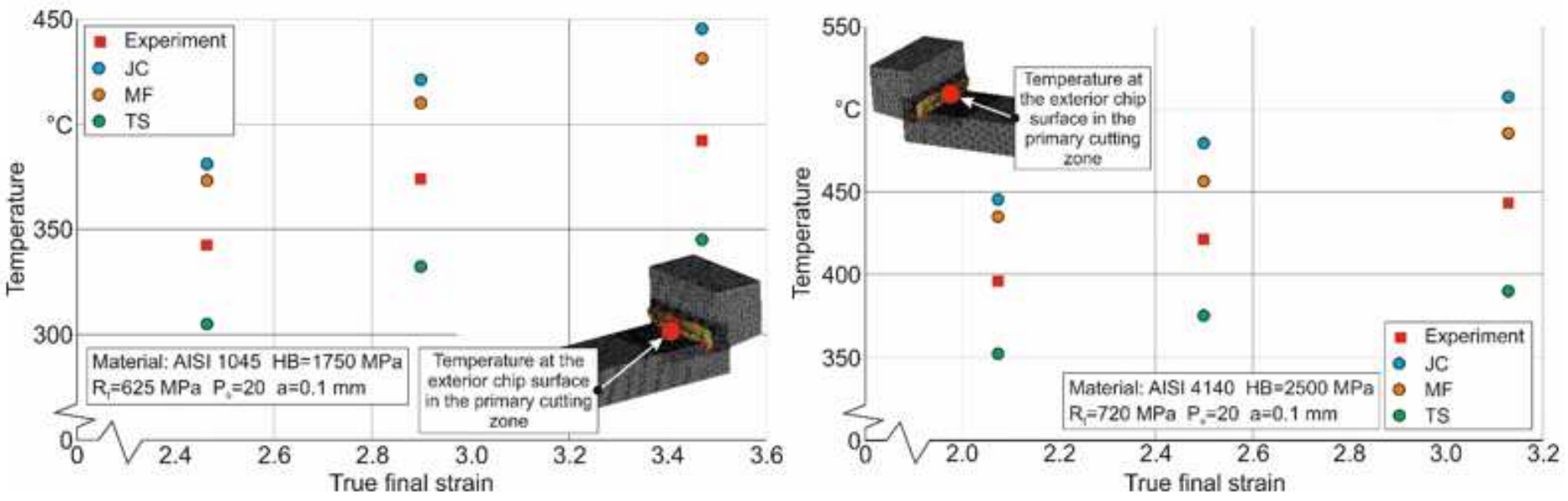

a)

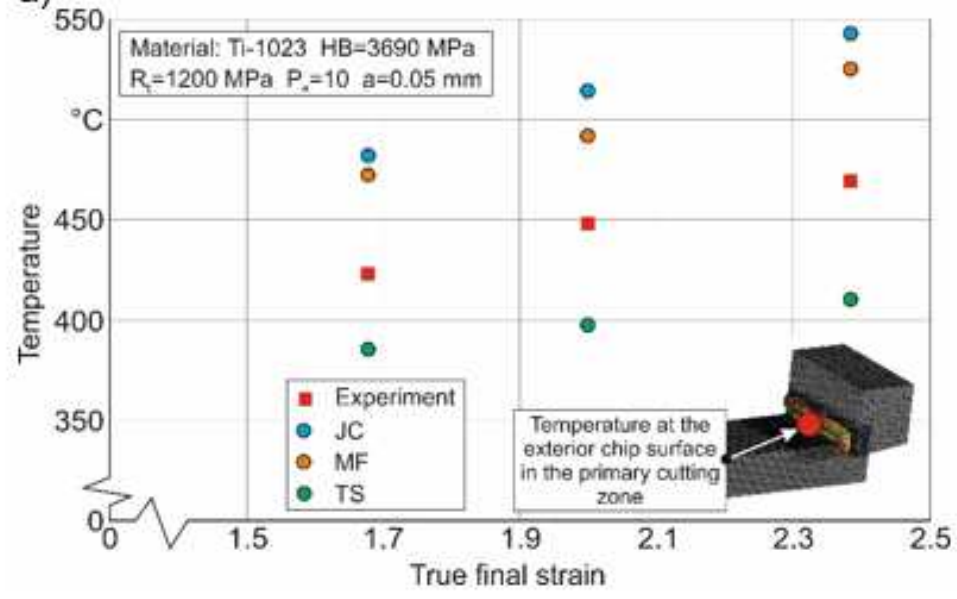

c)

b)

\section{Figure 7}

Comparison of experimental and simulated temperatures. 